\title{
Uncertainties of satellite-derived surface skin temperatures in the polar oceans: MODIS, AIRS/AMSU, and AIRS only
}

\author{
H.-J. Kang ${ }^{1}$, J.-M. Yoo ${ }^{2}$, M.-J. Jeong ${ }^{3}$, and Y.-I. Won ${ }^{4}$ \\ ${ }^{1}$ Department of Atmospheric Science and Engineering, Ewha Womans University, Seoul 120-750, Republic of Korea \\ ${ }^{2}$ Department of Science Education, Ewha Womans University, Seoul 120-750, Republic of Korea \\ ${ }^{3}$ Department of Atmospheric and Environmental Sciences, Gangneung-Wonju National University, \\ Gangneung 210-702, Republic of Korea \\ ${ }^{4}$ Wyle ST\&E, NASA/GSFC, Maryland, USA \\ Correspondence to: J.-M. Yoo (yjm@ewha.ac.kr)
}

Received: 11 February 2015 - Published in Atmos. Meas. Tech. Discuss.: 4 May 2015

Revised: 17 July 2015 - Accepted: 9 September 2015 - Published: 2 October 2015

\begin{abstract}
Uncertainties in the satellite-derived surface skin temperature (SST) data in the polar oceans during two periods (16-24 April and 15-23 September) 2003-2014 were investigated and the three data sets were intercompared as follows: MODerate Resolution Imaging Spectroradiometer Ice Surface Temperature (MODIS IST), the SST of the Atmospheric Infrared Sounder/Advanced Microwave Sounding Unit-A (AIRS/AMSU), and AIRS only. The AIRS only algorithm was developed in preparation for the degradation of the AMSU-A. MODIS IST was systematically warmer up to $1.65 \mathrm{~K}$ at the sea ice boundary and colder down to $-2.04 \mathrm{~K}$ in the polar sea ice regions of both the Arctic and Antarctic than that of the AIRS/AMSU. This difference in the results could have been caused by the surface classification method. The spatial correlation coefficient of the AIRS only to the AIRS/AMSU (0.992-0.999) method was greater than that of the MODIS IST to the AIRS/AMSU (0.968-0.994). The SST of the AIRS only compared to that of the AIRS/AMSU had a bias of $0.168 \mathrm{~K}$ with a RMSE of $0.590 \mathrm{~K}$ over the Northern Hemisphere high latitudes and a bias of $-0.109 \mathrm{~K}$ with a RMSE of $0.852 \mathrm{~K}$ over the Southern Hemisphere high latitudes. There was a systematic disagreement between the AIRS retrievals at the boundary of the sea ice, because the AIRS only algorithm utilized a less accurate GCM forecast over the seasonally varying frozen oceans than the microwave data. The three data sets (MODIS, AIRS/AMSU and AIRS only) showed significant warming rates $\left(2.3 \pm 1.7 \sim 2.8 \pm 1.9 \mathrm{~K} \mathrm{decade}^{-1}\right)$ in the northern high regions $\left(70-80^{\circ} \mathrm{N}\right)$ as expected from the ice-
\end{abstract}

albedo feedback. The systematic temperature disagreement associated with surface type classification had an impact on the resulting temperature trends.

\section{Introduction}

The satellite observations of the polar oceans have been more challenging than those of non-frozen ocean and land, because it is more difficult to identify clouds over the various surfaces (Tobin et al., 2006). The surface skin temperature (SST) is one of the most important climate variables that is related to the surface energy balance and the thermal state of the atmosphere (Jin et al., 1997). Compared to groundbased observations, satellite-observed SST data play a crucial role in climate study and model development by providing uniform resolution data encompassing the entire globe. The retrievals of AIRS data over the last decade have a significant contribution to various climate studies and model evaluations (Aumann et al., 2003; Tian et al., 2013; Yoo et al., 2013). AIRS retrievals have produced atmospheric temperature, moisture, and ozone profiles on a global scale by the AIRS method itself or together with other instruments (Liu at al., 2008). A lot of comparisons of the AIRS/AMSU data against data from numerical forecast model analysis fields, radiosondes, lidar, and retrievals from high-altitude aircraft have been used to assess the accuracy of the retrievals (Tobin et al., 2006; Susskind et al., 2014). The AIRS retrieval algorithm has been developed and validated gradually with clear 
sky and clear/cloudy conditions over a non-frozen ocean and then the non-polar land and polar cases (Tobin et al., 2006).

The AIRS/AMSU has an advantage of measuring the radiation penetrating through clouds and polar darkness, and has high spectral resolution and coarse spatial resolution (Dong et al., 2006). However, the AIRS only algorithm using only AIRS observations has been developed due to the degradation of the AMSU-A. Microwave and multispectral radiometers were used for global mapping of the sea ice extent and dynamics, while the visible, near-infrared, and infrared sensors could obtain details on the ice concentration, snow/ice albedo, thickness, and IST during clear-sky conditions (Hall et al., 2004; Scott et al., 2014). The MODIS on Earth Observing System (EOS) Aqua, used as infrared measurements, was influenced by water and cloud contamination, but had a higher spatial resolution (Dong et al., 2006). In order to remove the cloud effects in the MODIS IST algorithm, MODIS cloud mask products were used (Hall et al., 2004).

Since AIRS and MODIS were co-located on Aqua, they have often been used to make a synergistic algorithm and they have been compared to each other frequently (Molnar and Susskind, 2005; Li et al., 2012; Liu et al., 2014). Li et al. (2012) compared the atmospheric instability from at a single AIRS field of view (FOV; $\sim 13.5 \mathrm{~km}$ at nadir) sounding with that of AIRS/AMSU sounding $(\sim 45 \mathrm{~km})$, utilizing the MODIS cloud information. Molnar and Susskind (2005) validated the accuracy of the AIRS/AMSU cloud products using MODIS cloud analyses, which have a higher spatial resolution than that of AIRS. Knuteson et al. (2006) compared the MODIS Collection 4 (C4) with the AIRS Version 3 (V3) on the land surface temperature (LST) for the eastern half of the US, showing that the monthly differences were approximately $3 \mathrm{~K}$. Lee et al. (2013) investigated the characteristics of the differences between the MODIS land surface skin temperature/sea surface temperature and the AIRS/AMSU surface skin temperature across the globe, and found that the MODIS C5 product was systematically lower by $1.7 \mathrm{~K}$ than the AIRS/AMSU V5 product over land in the $50^{\circ} \mathrm{N}-50^{\circ} \mathrm{S}$ regions, but it was higher by $0.5 \mathrm{~K}$ than the AIRS/AMSU product over ocean. Particularly in the sea ice regions, the MODIS annual averages were larger than the AIRS/AMSU values, due to the differential errors in ice/snow emissivity between the retrieval methods (or channels) for the two data products. The differences between the MODIS and AIRS methods were reduced when the MODIS IST and AIRS/AMSU surface skin temperatures were compared for 9 days. The possible reasons for this include the local time of satellite observation difference between them due to the different swath width in the high latitude regions, and the emissivity difference between microwave and infrared channels, but more comparison studies are necessary for a longer period to pin down the reasons of such skin temperature discrepancies between MODIS and AIRS/AMSU.

The primary purpose of this study was to investigate a relative degree of agreement (or disagreement) among differ- ent SST data sets using the MODIS IST C5, the SST of the AIRS/AMSU, and AIRS only V6. The second purpose of this paper was to analyze the temperature trend differences affected by the temperature differences among different data products. The data sets used in this study were described in Sect. 2. In Sect. 3, we compared the MODIS and AIRS only data with the AIRS/AMSU values. We also analyzed the temperature trends from the three satellite-based data sets in Sect. 4, and in the conclusion we summarized our study.

\section{Data and methods}

The Aqua satellite carrying the AIRS, AMSU and MODIS instruments was launched on 4 May 2002 with the Earth's Radiant Energy System (CERES), Humidity Sounder for Brazil (HSB) and the Advanced Microwave Scanning Radiometer-EOS (AMSR-E). It has far exceeded its designed life span of 6 years and has a chance of operating into the 2020's (http://aqua.nasa.gov/). The Aqua satellite orbits the earth every $98.8 \mathrm{~min}$ with an equatorial crossing time going north (ascending) at 1:30 p.m. local time (daytime) and going south (descending) at 1:30 a.m. (nighttime) in a sunsynchronous, near polar orbit with an inclination of $98.2^{\circ}$ and an operational altitude of $705 \mathrm{~km}$ (Tian et al., 2013).

As shown in Table 1, we used the data sets of MODIS IST (e.g., Hall and Riggs, 2015) and SSTs of AIRS/AMSU and AIRS only over the Northern Hemisphere during 16-24 April and over the Southern Hemisphere on 15-23 September from 2003 to 2014 in order to avoid the polar night when the visible channels of the MODIS did not operate (Hall et al., 2004). The sea surface temperature observed from infrared channels of satellites indicates the values at the skin of sea water, in contrast with the sea surface temperature measured from buoys, of which values represent the temperature of bulk water near the sea surfaces. The infrared sea SST was measured at depths of approximately $10 \mu \mathrm{m}$ within the oceanic skin layer $(\sim 500 \mu \mathrm{m})$ at the water side of the airsea interface where the conductive and diffusive heat transfer processes dominated (Emery et al., 2001; Donlon et al., 2002; Liou, 2002).

As an imaging spectroradiometer, the MODIS with 36 bands has retrieved various physical parameters such as aerosol optical thickness, land and water surface temperature, leaf area index, and snow cover, etc. (Barnes et al., 1998; Hall and Riggs, 2007). MODIS produced the "sea ice by reflectance" and "IST" in order to identify sea ice (Riggs et al., 1999). The "sea ice by reflectance" was determined by the normalized difference snow index (NDSI), and the reflectance of Band $1(0.645 \mu \mathrm{m})$ and Band $2(0.858 \mu \mathrm{m})$. The NDSI was calculated using Band $4(0.555 \mu \mathrm{m})$ and Band 7 $(2.130 \mu \mathrm{m})$. IST is used as another method for identifying sea ice. The IST derived from the "split-window method" in Eq. (1), where bands 31 and 32 are centered at approximately 11 and $12 \mu \mathrm{m}$, respectively. The method was applied in order 
Table 1. The information on the satellite-observed surface skin temperature $\left(T_{\text {skin }}\right)$ Level 3 (L3) data used in this study. Three data sets of $T_{\text {skin }}$ were compared over the Northern Hemisphere during 16-24 April 2003-2014, and over the Southern Hemisphere during 1523 September 2003-2014. The abbreviations used in this table are as follows: temp (temperature), IST (ice surface skin temperature), OBS (observation), and SFC (surface).

\begin{tabular}{|c|c|c|c|c|c|c|c|c|}
\hline Satellite-observed data set & $\begin{array}{l}\text { Version } \\
\text { (Collection) }\end{array}$ & $\begin{array}{l}\text { Temp } \\
\text { type }\end{array}$ & Area & $\begin{array}{l}\text { Spatial } \\
\text { resolution }\end{array}$ & $\begin{array}{l}\text { Number } \\
\text { of OBS }\end{array}$ & Satellite sensor & Abbreviation & Reference \\
\hline MODIS IST & MYD29E1D/5 & Skin & Polar ocean & $4 \mathrm{~km} \times 4 \mathrm{~km}$ & 1 day $^{-1}$ & Aqua MODIS & $T_{\text {skin }}(\mathrm{MODIS})$ & Hall et al. (2004) \\
\hline AIRS/AMSU SFC skin temp & AIRX3STD/6 & Skin & Globe & $1^{\circ} \times 1^{\circ}$ & 2 day $^{-1}$ & Aqua AIRS/AMSU-A & $T_{\text {skin }}$ (AA_V6) & Susskind et al. (2014) \\
\hline AIRS only $\quad$ SFC skin temp & AIRS3STD/6 & Skin & Globe & $1^{\circ} \times 1^{\circ}$ & 2 day $^{-1}$ & Aqua AIRS & $T_{\text {skin }}\left(\mathrm{AO}_{-} \mathrm{V} 6\right)$ & Susskind et al. (2014) \\
\hline
\end{tabular}

to identify the ice when the IST was less than $271.5 \mathrm{~K}$. The cutoff temperature between water and ice $(271.5 \mathrm{~K})$ may vary depending on the region and season. The IST is calculated as follows:

$$
\begin{aligned}
\mathrm{IST} & =a+b T_{11}+c\left(T_{11}-T_{12}\right) \\
& +d\left[\left(T_{11}-T_{12}\right)(\sec (\theta)-1)\right],
\end{aligned}
$$

where $T_{11}$ is the brightness temperature $(\mathrm{K})$ in $11 \mu \mathrm{m}, T_{12}$ is the brightness temperature $(\mathrm{K})$ in $12 \mu \mathrm{m}$, and $\theta$ is the scan angle from nadir. The difference between the $T_{11}$ and the skin temperature from the LOWTRAN can be less than $3 \mathrm{~K}$ for a skin temperature between 230 and $260 \mathrm{~K}$ (Key et al., 1997). Since the value of $T_{11}$ itself was a good estimate, coefficients $a-d$ were defined for the following temperature ranges: $T_{11}<240 \mathrm{~K}, 240 \mathrm{~K} \leq T_{11} \leq 260 \mathrm{~K}$, and $260 \mathrm{~K}<T_{11}$ (Riggs et al., 2006). The IST algorithm was only applied to the polar ocean pixels that were determined to be clear by the MODIS cloud mask using visible reflectance (Hall et al., 2004). The surface in the IST algorithm was assumed to be snow (Key et al., 1997). MODIS ISTs were provided as daily polar fields with a $4 \mathrm{~km} \times 4 \mathrm{~km}$ resolution.

The AIRS spectrometer is a high spectral resolution spectrometer with 2378 channels in the thermal infrared spectrum and 4 bands in the visible spectrum (Won, 2008). The AIRS and AMSU were coupled in order to play a role as an advanced sounding system under clear and cloudy conditions (Aumann et al., 2003). The AIRS/AMSU algorithm is independent of the GCM, except for the use of GCM surface pressure to determine the bottom boundary conditions (Molnar and Susskind, 2005). V6 is the most current retrieval algorithm since the launch of AIRS instrument, and detailed descriptions are given in Olsen (2013b). The primary products from AIRS suite include the atmospheric temperaturehumidity profiles, ozone profiles, sea/land surface skin temperature (SST), and cloud related parameters such as the outgoing longwave radiation (OLR) (Susskind et al., 2011). In the AIRS/AMSU algorithm, the surface classification was conducted using the brightness temperature difference in $23 \mathrm{GHz}$ (AMSU ch1) and $50 \mathrm{GHz}$ (AMSU ch3). The difference (brightness temperature at $23 \mathrm{GHz}$ minus brightness temperature at $50 \mathrm{GHz}$ ) had a negative value on the sea ice and a positive value on the water (Grody et al., 1999; Hewison and English, 1999). Also, the brightness temperature dif- ference between $23 \mathrm{GHz}$ (AMSU ch1) and $31 \mathrm{GHz}$ (AMSU ch2) could distinguish the age of the sea ice (Kongoli et al., 2008). The accuracy of AIRS/AMSU SST can be affected by surface misclassification, which is caused by the surface emissivity changes, the pixel mixed with the various surface types, and the ice pixel pooled with water.

After the surface type classification from the AMSU retrieval, the initial state for atmospheric and surface parameters, cloud parameters and OLR was generated using the Neural Network methodology (Susskind et al., 2011, 2014). The methodology was used to approximate some functions between the input and output vectors by training (Gardner and Dorling, 1998). Next, the initial clear column radiances were generated, which were based on the initial state and the observed infrared radiances. The surface and atmospheric variables, including the surface skin temperature, were retrieved by updating the cloud-cleared infrared radiance, iteratively. The cloud properties and outgoing longwave radiation were then retrieved, followed by the error estimates and quality control. In the AIRS only V6, shortwave window region 3.76-4.0 $\mu \mathrm{m}$ was used in order to derive the surface skin temperature and surface spectral emissivity $(\varepsilon)$.

AMSU channels 4-5 had not been available since 2007 and 2010, respectively, due to radiometric noise. In preparation for the degradation of the other AMSU channels, the AIRS only algorithm was developed excluding the AMSU observations. The algorithm was similar to that of AIRS/AMSU, but it did not use the AMSU-A observations in any step of the physical retrieval process and the quality control methodology. The AIRS only algorithm has utilized the forecast surface temperature from the NOAA Global Forecast System (GFS) in order to determine whether the oceanic surface is highly likely to be liquid or frozen, instead of AMSU observations (Olsen, 2013a; Susskind et al., 2014).

AIRS/AMSU L2 product (AIRX2RET) is based on $3 \times 3$ AIRS FOVs coexisting within a single AMSU footprint, and the horizontal resolution of AIRS and AMSU is approximately 13.5 and $45 \mathrm{~km}$, respectively (Aumann et al., 2003; Zheng et al., 2015). The L2 data set of AIRS only is provided on $3 \times 3$ AIRS FOVs $(\sim 45 \mathrm{~km})$ like that of AIRS/AMSU. The two L3 products of the AIRS/AMSU and AIRS only data sets used in this study have also been analyzed under 
the same spatial resolution of a $1^{\circ} \times 1^{\circ}(\sim 100 \mathrm{~km} \times 100 \mathrm{~km})$ grid (Table 1).

We calculated the climatology and anomaly values from the yearly 9 -day mean temperatures in a $1^{\circ} \times 1^{\circ}$ grid for the 12 -year period of Aqua satellite observations in order to estimate the temperature anomaly trends. The trends of MODIS IST were derived only when the number of yearly data was at least 10 out of 12 entire years at each grid point. The trends of the AIRS/AMSU and AIRS only were derived only when the number of yearly data sets was 12 , covering the entire years of the analysis at each grid. The bootstrap method (Wilks, 1995) was used to calculate at a $95 \%$ confidence interval. In the method, 10000 linear temperature trends were generated by random sampling, allowing repetition of 10000 yearly anomaly temperature data sets. Then, we estimated the $95 \%$ confidence interval of 10000 temperature trends.

\section{Comparison of the satellite-derived surface skin temperatures: IST vs. SST}

Figure 1a shows the spatial coverage and the averaged value of the MODIS IST over the Southern Hemisphere during 1523 September 2003-2014. In order to solve the spatial resolution mismatches, the original resolution of the MODIS data with a $4 \mathrm{~km} \times 4 \mathrm{~km}$ grid (Fig. 1a) was re-gridded to a $1^{\circ} \times 1^{\circ}$ grid in the case of MODIS data present over $50 \%$ (Fig. 1b). A grid spacing of $1^{\circ}$ corresponds to approximately $111 \mathrm{~km}$ on the equator, and it becomes reduced poleward. In the zonal averaged SST analysis, this $50 \%$ criterion was used. During the same period, the spatial distributions of the climatological $T_{\text {skin }}\left(\mathrm{AA} \_\mathrm{V} 6\right.$ ) and $T_{\text {skin }}\left(\mathrm{AO} \_\mathrm{V} 6\right)$ were also shown in Fig. 1c-d, respectively. As expected, the MODIS and AIRS showed the spatial distribution of the climatological SST, warmer at the lower latitudes than the higher latitudes. The SST distributions over the Northern Hemisphere during 16-24 April 2003-2014 have been shown in Kang and Yoo (2015).

Figure 2a displays the number of years when both $T_{\text {skin }}$ (MODIS) and $T_{\text {skin }}$ (AA_V6) are available at each grid point over the Southern Hemisphere. The number near $60^{\circ} \mathrm{S}$ was smaller than that of the other regions because the MODIS IST algorithm only produced its data in the cloud-free pixels. Similar distributions by the clouds were shown in Fig. $2 b$ and $2 \mathrm{~d}$ for the same reason. The reduced number of observations near $60^{\circ} \mathrm{S}$ had a spatial distribution similar to that of the frontal cloud bands that were likely associated with the mid-/high-latitude depressions encircling the Antarctica (e.g., Jakob, 1999; Comiso and Stock, 2001; Lachlan-Cope, 2010; Boucher et al., 2013). Figure 2c shows the number of years when both $T_{\text {skin }}\left(\mathrm{AO} \_\mathrm{V} 6\right.$ ) and $T_{\text {skin }}$ (AA_V6) were available at each grid. Most of the grids had both $T_{\text {skin }}$ (AO_V6) and $T_{\text {skin }}$ (AA_V6) for a period of more than 10 years.

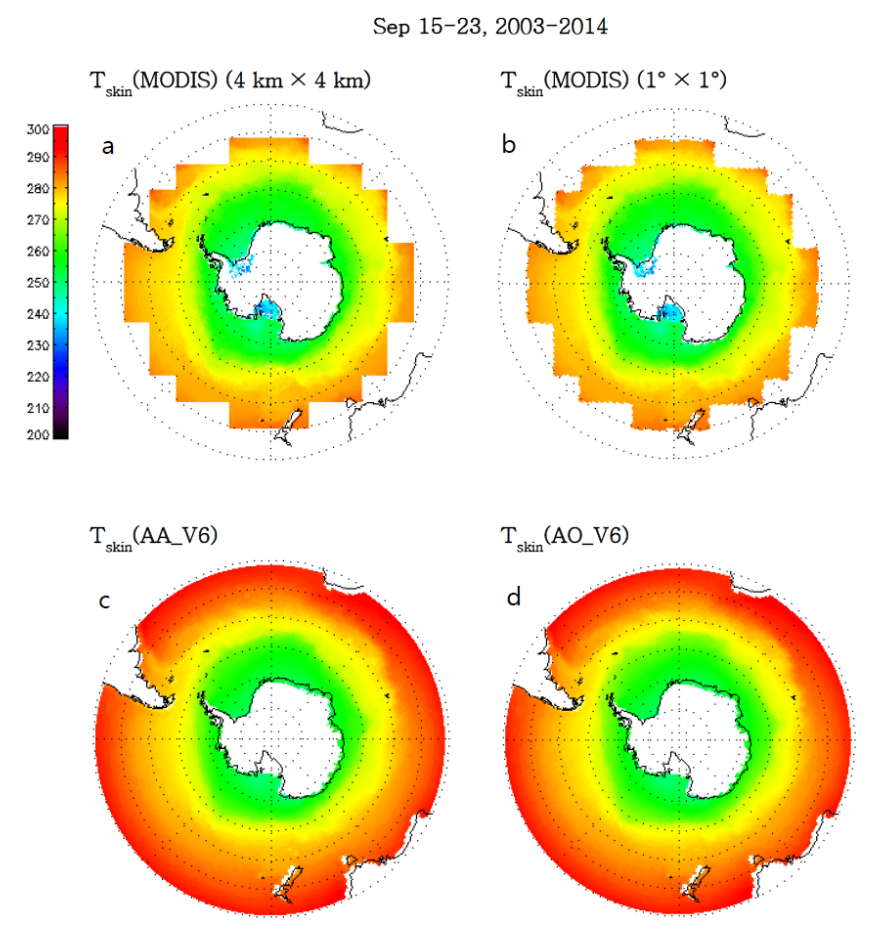

Figure 1. (a) 12-year composite skin temperatures (K) of the MODIS IST over the Southern Hemisphere during 15-23 September 2003-2014. The original MODIS data (MYD29E1D) have a $4 \mathrm{~km} \times 4 \mathrm{~km}$ spatial resolution. Their spatial resolution has been reconstructed to $1^{\circ} \times 1^{\circ}$ in (b) in order to compare this data with the AIRS/AMSU data. (c)-(d) is the surface skin temperatures of the AIRS/AMSU and AIRS only over the Southern Hemisphere ocean during 15-23 September 2003-2014, respectively.

Figure $3 \mathrm{a}$ presents the spatial distribution of the temporal difference in a $1^{\circ} \times 1^{\circ}$ grid between the climatological $T_{\text {skin }}$ (MODIS) and $T_{\text {skin }}$ (AA_V6) during 16-24 April 2003-2014 over the Northern Hemisphere. In general, $T_{\text {skin }}$ (MODIS) at $60-70^{\circ} \mathrm{N}$ was higher than the $T_{\text {skin }}$ (AA_V6). $T_{\text {skin }}$ (MODIS) was about $3 \mathrm{~K}$ higher than the $T_{\text {skin }}$ (AA_V6) on the Hudson Bay and near Greenland, whereas it was about $-2 \mathrm{~K}$ lower near the center of the Arctic Ocean. The relationship between the climatological $T_{\text {skin }}$ (MODIS) and $T_{\text {skin }}$ (AA_V6) was presented in the scatter diagrams (Fig. 3b). The scatter plot revealed a temperature interval which deviated from the simple linear line. The discontinuous shape appeared at the freezing point $(\sim 273 \mathrm{~K})$ and the turning point ( $\sim 260 \mathrm{~K}$ ) in terms of $T_{\text {skin }}$ (MODIS), changing the coefficient of the MODIS IST algorithm. In the interval, $T_{\text {skin }}$ (MODIS) was systematically higher than the $T_{\text {skin }}$ (AA_V6) in the $260-273 \mathrm{~K}$ range of $T_{\text {skin }}$ (MODIS). The slope in the range was 0.85 , lower than the slope for the whole regression line (0.97). There was a better agreement in the $240-260 \mathrm{~K}$ range, where the difference between the $T_{11}$ and the SST in the LOWTRAN was less than $3 \mathrm{~K}$ (Key et al., 1997). The 

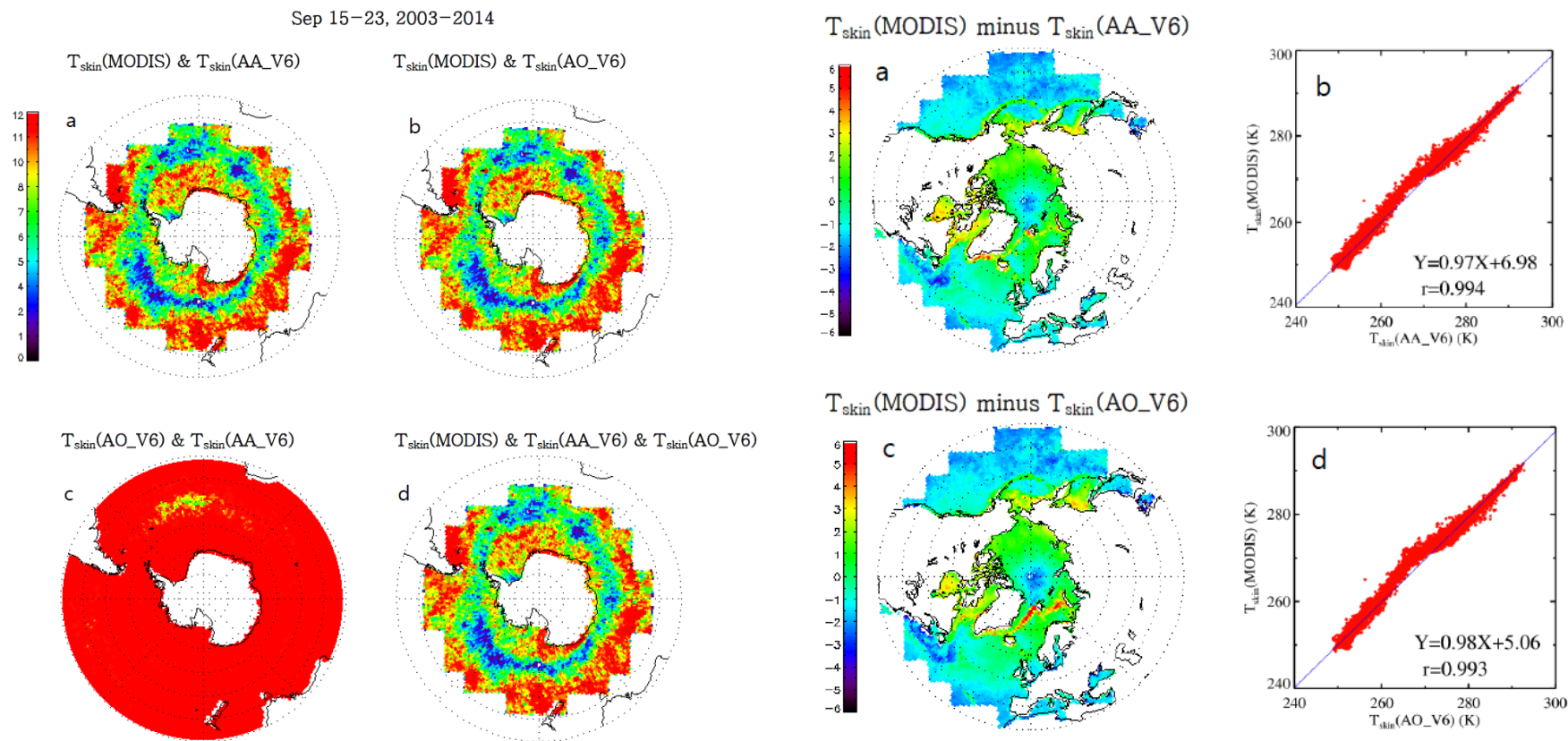

Figure 2. The number of co-located observations of (a) $T_{\text {skin }}$ (MODIS) and $T_{\text {skin }}$ (AA_V6), (b) $T_{\text {skin }}$ (MODIS) and $T_{\text {skin }}$ (AO_V6), and (c) $T_{\text {skin }}\left(\mathrm{AO} \_\mathrm{V} 6\right.$ ) and $T_{\text {skin }}$ (AA_V6) over the Southern Hemisphere during 15-23 September 2003-2014. (d) Same as in (c) except for three different data sets $\left(T_{\text {skin }}\right.$ (MODIS), $T_{\text {skin }}\left(\mathrm{AA} \_\mathrm{V} 6\right)$, and $T_{\text {skin }}\left(\mathrm{AO} \_\mathrm{V} 6\right)$ ).

better agreement in the range greater than $280 \mathrm{~K}$ was also shown.

Figure $3 \mathrm{c}$ was the same as Fig. 3a except for $T_{\text {skin }}$ (MODIS) vs. $T_{\text {skin }}\left(\mathrm{AO}_{-} \mathrm{V} 6\right)$. The differences between the two data sets were very similar to those in Fig. 3a. However, $T_{\text {skin }}$ (MODIS) was more than $4 \mathrm{~K}$ higher than $T_{\text {skin }}$ (AO_V6) in some regions near the Greenland and the Barents Sea. The slope (0.93) in the $260-273 \mathrm{~K}$ range of $T_{\text {skin }}$ (MODIS) also indicated a deviation from the total slope (0.98) in the scatter plot (Fig. 3d), similar to that in Fig. 3b. Figure 3e showed the difference between $T_{\text {skin }}\left(\right.$ AO_V6) to $T_{\text {skin }}$ (AA_V6). Overall, the agreement was much better than the previous two cases (Fig. 3a and c), except for in the Greenland Sea, the Barents Sea, and the Okhotsk Sea. Both $T_{\text {skin }}($ AO_V6) and $T_{\text {skin }}($ AA_V6) agreed with each other $(r=0.999)$ well except for near the freezing point.

Figure 4 showed discrepancies among the three types of SST data sets over the Southern Hemisphere during 1523 September 2003-2014. It has been noted that there was a latitudinal band encircling Antarctica at $60-70^{\circ} \mathrm{S}$, where $T_{\text {skin }}$ (MODIS) was higher than both the $T_{\text {skin }}\left(\mathrm{AA} \_\mathrm{V} 6\right.$ ) and $T_{\text {skin }}($ AO_V6) (Fig. 4a and c). The circular region corresponded to the sea ice/water boundary which was expected to move seasonally. This implies a systematic difference between $T_{\text {skin }}$ (MODIS) and $T_{\text {skin }}$ (AA_V6) in the sea ice classification. The corresponding scatter plots also revealed a dis-

$\mathrm{T}_{\text {skin }}\left(\mathrm{AO} \_\mathrm{V6}\right.$ ) minus $\mathrm{T}_{\text {skin }}($ AA_V6)
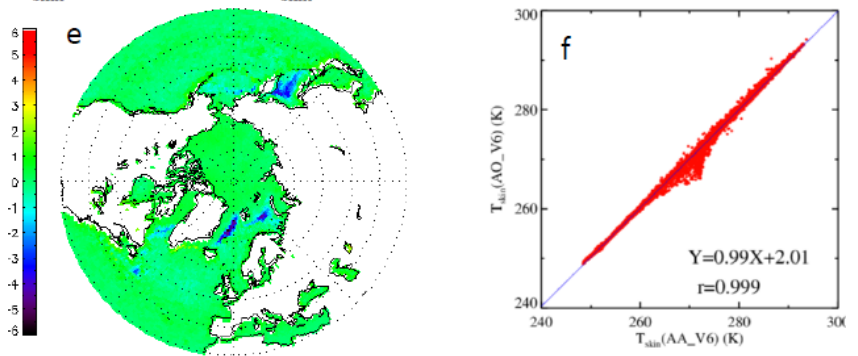

Figure 3. The distributions of (a) $T_{\text {skin }}$ (MODIS) minus $T_{\text {skin }}$ (AA_V6), (c) $T_{\text {skin }}$ (MODIS) minus $T_{\text {skin }}\left(\right.$ AO_V6), and (e) $T_{\text {skin }}$ (AO_V6) minus $T_{\text {skin }}($ AA_V6) over the Northern Hemisphere during 16-24 April 2003-2014. The scatter plots of (b) $T_{\text {skin }}$ (MODIS) vs. $T_{\text {skin }}\left(\mathrm{AA} \_\mathrm{V} 6\right),(\mathbf{d}) T_{\text {skin }}(\mathrm{MODIS})$ vs. $T_{\text {skin }}\left(\mathrm{AO} \_\mathrm{V} 6\right)$, and (f) $T_{\text {skin }}\left(\right.$ AO_V6) vs. $T_{\text {skin }}\left(\mathrm{AA} \_\right.$V6).

continuous (i.e., not linear) shape in the $260-273 \mathrm{~K}$ range of $T_{\text {skin }}$ (MODIS) (Fig. $4 \mathrm{~b}$ and d). The slopes in that range were 0.84-0.94, which were smaller than the slope $(0.98)$ in the whole range. In addition, $T_{\text {skin }}$ (MODIS) showed lower temperature values than $T_{\text {skin }}\left(\mathrm{AA} \_\mathrm{V} 6\right)$ and $T_{\text {skin }}\left(\mathrm{AO} \_\mathrm{V} 6\right)$ near the Antarctic peninsula, in the region from Weddell Sea to Ross Sea (Fig. 4a and c).

The comparison between two types of AIRS data sets also showed the circular pattern around Antarctica where $T_{\text {skin }}\left(\right.$ AO_V6) was lower by $1.5-5.6 \mathrm{~K}$ than $T_{\text {skin }}$ (AA_V6) (Fig. 4e). The discrepancy near the sea ice/water boundary was clear, possibly due to the difference in the sea ice detection method between the two data sets. The uncertainty of the SST at the sea ice boundary was distinguished from the other regions. Both $T_{\text {skin }}\left(\mathrm{AO} \_\mathrm{V} 6\right)$ and $T_{\text {skin }}\left(\mathrm{AA} \_\mathrm{V} 6\right)$ were in good agreement, other than the sea ice/water boundary re- 

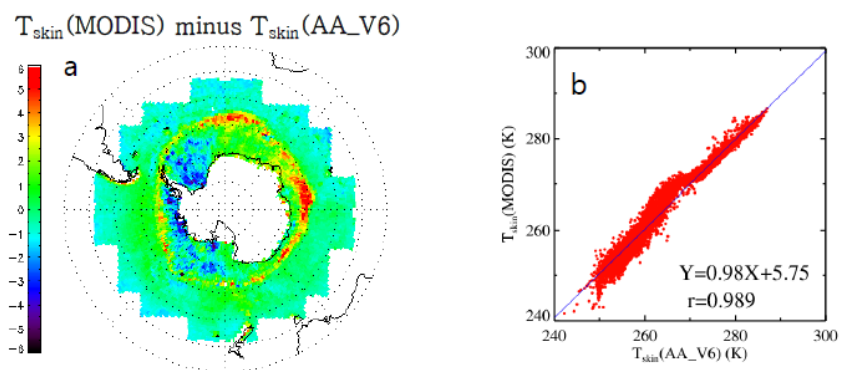

$\mathrm{T}_{\text {skin }}$ (MODIS) minus $\mathrm{T}_{\text {skin }}$ (AO_V6)

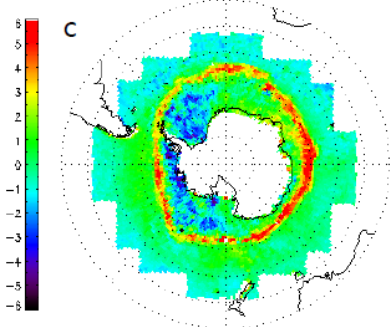

$\mathrm{T}_{\text {skin }}\left(\mathrm{AO}\right.$ _V6) minus $\mathrm{T}_{\text {skin }}$ (AA_V6)
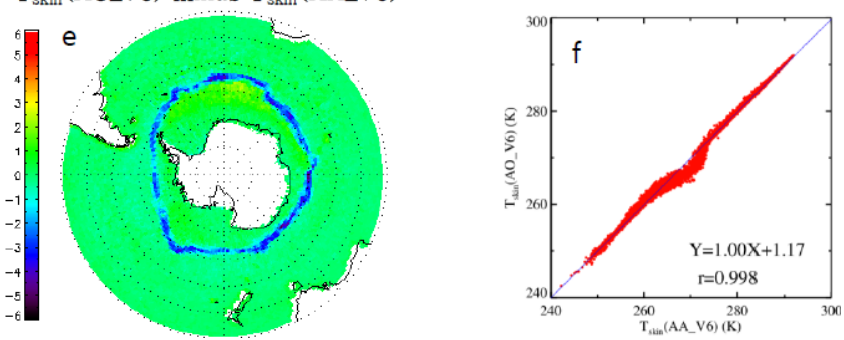

Figure 4. Same as in Fig. 3 except for the data taken during 1523 September 2003-2014, over the Southern Hemisphere.

gions. The scatter pattern of the $T_{\text {skin }}\left(\mathrm{AA} \_\mathrm{V} 6\right)$ vs. that of the $T_{\text {skin }}($ AO_V6) showed that the two data sets generally agreed with each other, but the disagreement near the freezing point again occurred indicating a cold bias of AIRS only with respect to AIRS/AMSU (Fig. 4f).

Figure 5 showed the annual-average spatial distributions for $T_{\text {skin }}$ (MODIS) minus $T_{\text {skin }}$ (AA_V6) in the Southern Hemisphere from 15-23 September 2003-2014. Although the 9-day composite values were used in each year, $T_{\text {skin }}$ (MODIS) data did not exist in some areas. It was because the MODIS IST algorithm was valid only for cloud-free pixels. The systematic positive values at the boundary of the sea ice consistently occurred, while the negative ones occurred on some areas of the sea ice near Antarctica every year.

Figure 6 presented the interannual variation of the spatial distribution of $T_{\text {skin }}\left(\right.$ AO_V6) minus $T_{\text {skin }}($ AA_V6) for the study period. As already seen in Fig. 4e, the values of $T_{\text {skin }}$ (AO_V6) compared to $T_{\text {skin }}$ (AA_V6) show systematic negative values encircling Antarctica during the period. In addition, there were positive values over the sea-ice prevailing areas inside the circle, with the location varying from year to year, which must be related to the difference in the surface type characterization.

Table 2 showed the statistics of bias, spatial correlation coefficient $(r)$, and root mean square error (RMSE) obtained from the 12-year climatologies of 2003-2014 in order to analyze the systematic error among the three types of satelliteobserved temperatures quantitatively. This analysis for each hemispheric vernal period has been performed over the two regions $\left(35-90,60-90^{\circ} \mathrm{N}\right)$ of the Northern Hemisphere during 16-24 April, and over the regions $\left(40-90,60-90^{\circ} \mathrm{S}\right)$ of the Southern Hemisphere during 15-23 September. The spatial correlation coefficient between the two satellite data sets was computed in this study as follows. (i) The climatological 9-day composite data of SSTs during 2003-2014 were computed in a $1^{\circ} \times 1^{\circ}$ grid of the two data sets, respectively. (ii) We computed the spatial correlation coefficient between the two data sets, using their climatological values in a $1^{\circ} \times 1^{\circ}$ grid within a given latitude band. The values in parentheses indicated the average obtained from the statistics for each year and their corresponding standard deviations. Based on the climatology values, the SST of the AIRS retrievals were comparable with respect to the $T_{\text {skin }}$ (MODIS) ( $r=0.959-0.994)$. $T_{\text {skin }}$ (MODIS) tended to systematically exceed the AIRS retrievals over the polar oceans (bias $=0.198-0.597 \mathrm{~K}$ ). Hall et al. (2004) reported the accuracy of $T_{\text {skin }}$ (MODIS) with the bias values of $1.2-1.3 \mathrm{~K}$ near the South Pole and the Arctic Ocean. The RMSE of $1.847 \mathrm{~K}$ for $T_{\text {skin }}$ (MODIS) vs. the $T_{\text {skin }}\left(\mathrm{AA} \_\mathrm{V} 6\right.$ ) over $60-90^{\circ} \mathrm{S}$ in our study was slightly higher than that in the study of Hall et al. (2004).

From the intercomparison of the three data sets, the bias $(-0.109-0.597)$ and RMSE $(0.590-2.173)$ over the high latitude belt $\left(60-90^{\circ} \mathrm{N}\right.$ and $\left.{ }^{\circ} \mathrm{S}\right)$ tended to be larger, and the correlation coefficients $(r=0.959-0.986)$ was smaller than those over $35-90^{\circ} \mathrm{N}$ and $40-90^{\circ} \mathrm{S}$ among the three comparisons (Table 2). This result indicated that there was more disagreement over the high latitudes than over other regions. The spatial correlation coefficient (0.992-0.999) between $T_{\text {skin }}\left(\mathrm{AO} \_\mathrm{V} 6\right)$ and $T_{\text {skin }}\left(\mathrm{AA} \_\mathrm{V} 6\right)$ was greater than those (0.968-0.994) between $T_{\text {skin }}$ (MODIS) and $T_{\text {skin }}$ (AA_V6). In the high latitudes $T_{\text {skin }}\left(A_{-}\right.$_V6) with respect to $T_{\text {skin }}$ (AA_V6) had a positive bias of $0.168 \mathrm{~K}$ with a RMSE of $0.590 \mathrm{~K}$ in the Northern Hemisphere, but a bias of $-0.109 \mathrm{~K}$ with a RMSE of $0.852 \mathrm{~K}$ in the Southern Hemisphere. The high correlations $(r=0.998-0.999)$ between the AIRS/AMSU and AIRS only (i.e., AIRS retrievals) over the $35-90^{\circ} \mathrm{N}$ and $40-90^{\circ} \mathrm{S}$ areas showed that the AIRS only can be a good alternative for the AIRS/AMSU, except for at the region of the sea ice boundary $(r=0.992$ over the 60 $90^{\circ} \mathrm{S}$ ). The disagreement between $T_{\text {skin }}\left(\mathrm{AA} \_\mathrm{V} 6\right)$ and $T_{\text {skin }}$ (AO_V6) at the region where the sea ice and water mixed appeared, because the AIRS only used less accurate GCM forecast data for surface classification over the potentially frozen oceans. 
a) 2003

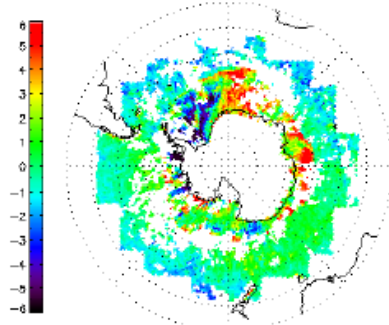

d) 2006

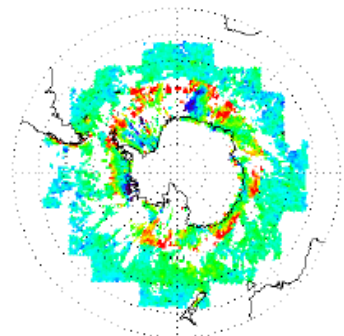

g) 2009

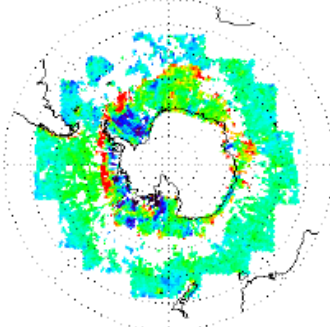

j) 2012

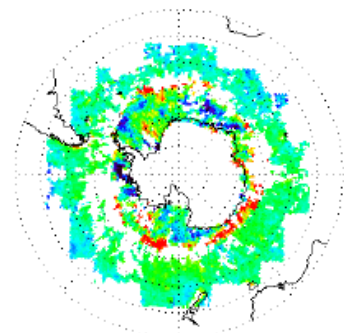

b) 2004

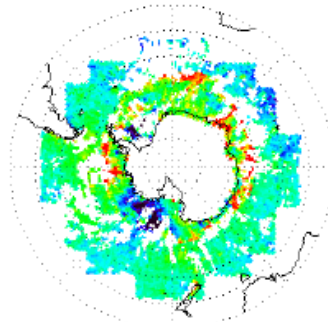

e) 2007

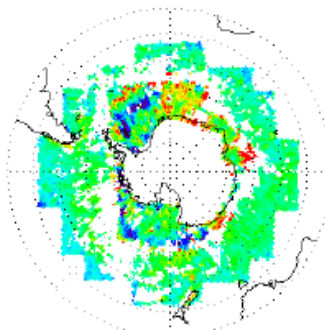

h) 2010

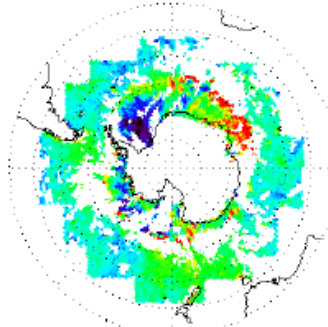

k) 2013

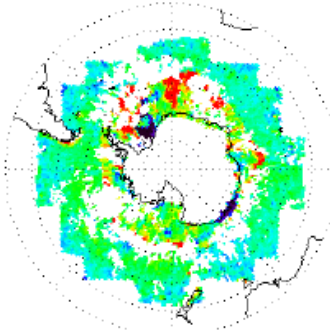

c) 2005

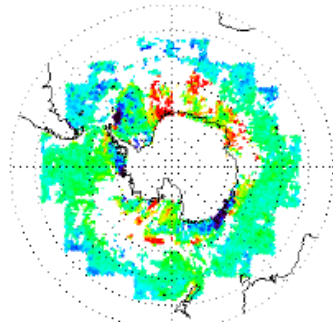

f) 2008

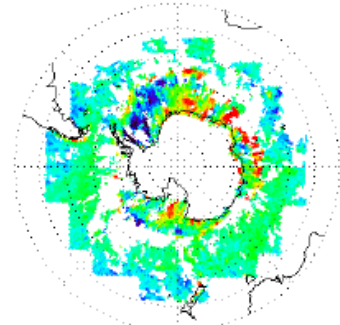

i) 2011

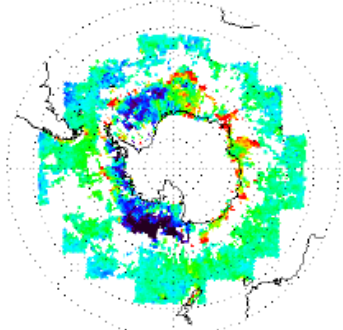

1) 2014

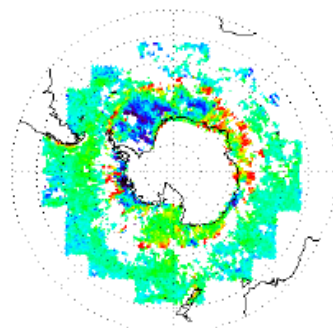

Figure 5. Annual-average spatial distributions of the $T_{\text {skin }}$ (MODIS) minus $T_{\text {skin }}$ (AA_V6) over the Southern Hemisphere during 1523 September.

Figure 7 presents the zonal mean temperature difference among the three satellite-observed data sets in a $1^{\circ} \times 1^{\circ}$ grid over the Northern Hemisphere during 16-24 April 2003-2014 and over the Southern Hemisphere during 1523 September 2003-2014. The red, blue and green lines represent the zonally averaged annual values of $T_{\text {skin }}$ (MODIS) minus $T_{\text {skin }}\left(\mathrm{AA} \_\mathrm{V} 6\right), T_{\text {skin }}(\mathrm{MODIS}) \operatorname{minus} T_{\text {skin }}\left(\mathrm{AO} \_\mathrm{V} 6\right)$, and $T_{\text {skin }}\left(\right.$ AO_V6) minus $T_{\text {skin }}$ (AA_V6), respectively. The climatological annual values have been calculated from the interannually varying yearly data, shown in Fig. 8. The black dashed line, the difference between the original MODIS IST data $(4 \mathrm{~km} \times 4 \mathrm{~km})$ and converted $T_{\text {skin }}($ MODIS $)\left(1^{\circ} \times 1^{\circ}\right)$ indicated the possible error from the conversion of spatial resolution. The differences by the conversion over both hemispheres were within 0.3 and $0.5 \mathrm{~K}$, respectively. The original $T_{\text {skin }}$ (MODIS), converted $T_{\text {skin }}$ (MODIS), $T_{\text {skin }}\left(\mathrm{AA} \_\mathrm{V} 6\right.$ ), and $T_{\text {skin }}($ AO_V6) were chosen under the same condition in space and time, and each grid $\left(1^{\circ} \times 1^{\circ}\right)$ of a degree latitudinal band.

It is hard to see in Fig. 3a the systematic difference due to the sea ice detection over the Northern Hemisphere because of the continental distribution. However, Fig. 7 clearly showed that the difference among the $T_{\text {skin }}$ (MODIS), $T_{\text {skin }}$ (AA_V6), and $T_{\text {skin }}$ (AO_V6) existed over the Northern Hemisphere. $T_{\text {skin }}$ (MODIS) was warmer than $T_{\text {skin }}$ (AA_V6) in $56-81^{\circ} \mathrm{N}$ and $54-69^{\circ} \mathrm{S}$, while cooler than $T_{\text {skin }}$ (AA_V6) 
Table 2. Statistical comparisons of the climatological 9-day composite data during 2003-2014 over both hemispheres; $T_{\text {skin }}$ (MODIS) vs. $T_{\text {skin }}\left(\mathrm{AA} \_\mathrm{V} 6\right), T_{\text {skin }}(\mathrm{MODIS})$ vs. $T_{\text {skin }}\left(\mathrm{AO} \_\mathrm{V} 6\right.$ ), and $T_{\text {skin }}\left(\mathrm{AO} \_\mathrm{V} 6\right)$ vs. $T_{\text {skin }}$ (AA_V6). The values in this table were calculated based on the 12-year composite mean values. The values in parentheses indicate the 12-year mean values and their standard deviations during 2003-2014. Bias: $T_{\text {skin }}$ (MODIS) minus $T_{\text {skin }}\left(\right.$ AA_V6), $T_{\text {skin }}$ (MODIS) minus $T_{\text {skin }}\left(\right.$ AO_V6), and $T_{\text {skin }}\left(\right.$ AO_V6) minus $T_{\text {skin }}($ AA_V6), $r$ : correlation coefficient, RMSE: root mean square error.

\begin{tabular}{|c|c|c|c|c|c|c|c|c|c|}
\hline \multirow[t]{2}{*}{ Region } & \multicolumn{3}{|c|}{$T_{\text {skin }}(\mathrm{MODIS})$ vs. $T_{\text {skin }}\left(\mathrm{AA} \_\mathrm{V} 6\right)$} & \multicolumn{3}{|c|}{$T_{\text {skin }}(\mathrm{MODIS})$ vs. $T_{\text {skin }}\left(\mathrm{AO} \_\mathrm{V} 6\right)$} & \multicolumn{3}{|c|}{$T_{\text {skin }}\left(\right.$ AO_V6) vs. $T_{\text {skin }}($ AA_V6) } \\
\hline & Bias $(\mathrm{K})$ & $r$ & RMSE (K) & Bias $(\mathrm{K})$ & $r$ & RMSE (K) & Bias $(\mathrm{K})$ & $r$ & RMSE (K) \\
\hline $35-90^{\circ} \mathrm{N}$ & $\begin{array}{l}-0.169 \\
(-0.161 \pm 0.231)\end{array}$ & $\begin{array}{l}0.994 \\
(0.990 \pm 0.002)\end{array}$ & $\begin{array}{l}1.491 \\
(1.909 \pm 0.156)\end{array}$ & $\begin{array}{l}-0.289 \\
(-0.324 \pm 0.308)\end{array}$ & $\begin{array}{l}0.993 \\
(0.990 \pm 0.003)\end{array}$ & $\begin{array}{l}1.563 \\
(1.963 \pm 0.260)\end{array}$ & $\begin{array}{l}0.133 \\
(0.137 \pm 0.130)\end{array}$ & $\begin{array}{l}0.999 \\
(0.997 \pm 0.001)\end{array}$ & $\begin{array}{l}0.574 \\
(1.018 \pm 0.131)\end{array}$ \\
\hline $40-90^{\circ} \mathrm{S}$ & $\begin{array}{l}0.026 \\
(-0.010 \pm 0.218)\end{array}$ & $\begin{array}{l}0.989 \\
(0.982 \pm 0.003)\end{array}$ & $\begin{array}{l}1.480 \\
(2.082 \pm 0.144)\end{array}$ & $\begin{array}{l}0.203 \\
(0.035 \pm 0.282)\end{array}$ & $\begin{array}{l}0.985 \\
(0.980 \pm 0.003)\end{array}$ & $\begin{array}{l}1.756 \\
(2.184 \pm 0.119)\end{array}$ & $\begin{array}{l}-0.141 \\
(-0.139 \pm 0.079)\end{array}$ & $\begin{array}{l}0.998 \\
(0.994 \pm 0.001)\end{array}$ & $\begin{array}{l}0.750 \\
(1.272 \pm 0.092)\end{array}$ \\
\hline $60-90^{\circ} \mathrm{N}$ & $\begin{array}{l}0.223 \\
(0.194 \pm 0.357)\end{array}$ & $\begin{array}{l}0.986 \\
(0.973 \pm 0.009)\end{array}$ & $\begin{array}{l}1.501 \\
(1.986 \pm 0.227)\end{array}$ & $\begin{array}{l}0.597 \\
(-0.013 \pm 0.475)\end{array}$ & $\begin{array}{l}0.986 \\
(0.972 \pm 0.011)\end{array}$ & $\begin{array}{l}1.591 \\
(2.033 \pm 0.370)\end{array}$ & $\begin{array}{l}0.168 \\
(0.170 \pm 0.214)\end{array}$ & $\begin{array}{l}0.998 \\
(0.992 \pm 0.003)\end{array}$ & $\begin{array}{l}0.590 \\
(1.027 \pm 0.216)\end{array}$ \\
\hline $60-90^{\circ} \mathrm{S}$ & $\begin{array}{l}0.198 \\
(0.368 \pm 0.537)\end{array}$ & $\begin{array}{l}0.968 \\
(0.906 \pm 0.023)\end{array}$ & $\begin{array}{l}1.847 \\
(2.871 \pm 0.276)\end{array}$ & $\begin{array}{l}0.306 \\
(0.295 \pm 0.620)\end{array}$ & $\begin{array}{l}0.959 \\
(0.898 \pm 0.021)\end{array}$ & $\begin{array}{l}2.173 \\
(2.987 \pm 0.271)\end{array}$ & $\begin{array}{l}-0.109 \\
(-0.108 \pm 0.142)\end{array}$ & $\begin{array}{l}0.992 \\
(0.976 \pm 0.005)\end{array}$ & $\begin{array}{l}0.852 \\
(1.498 \pm 0.112)\end{array}$ \\
\hline
\end{tabular}

a) 2003

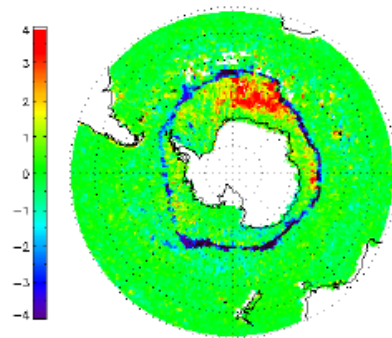

d) 2006

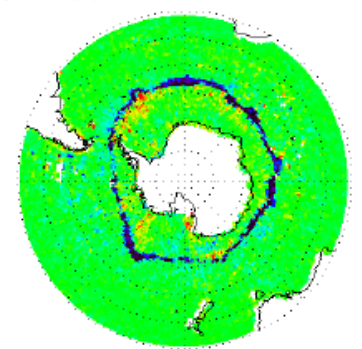

g) 2009

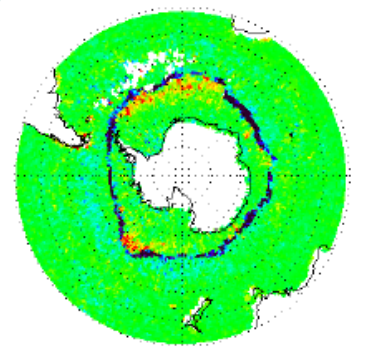

j) 2012

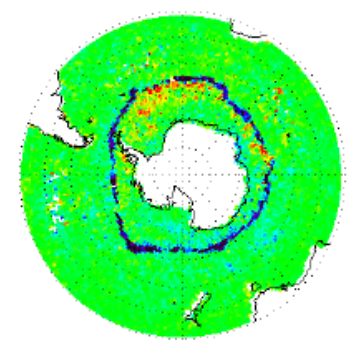

b) 2004

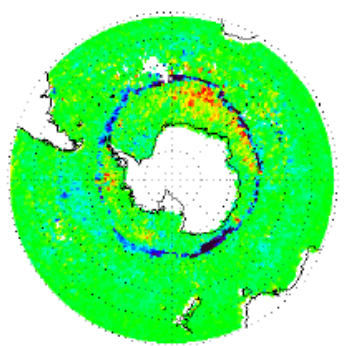

e) 2007

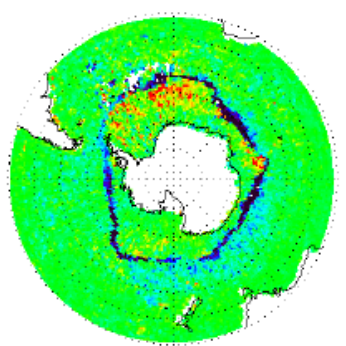

h) 2010

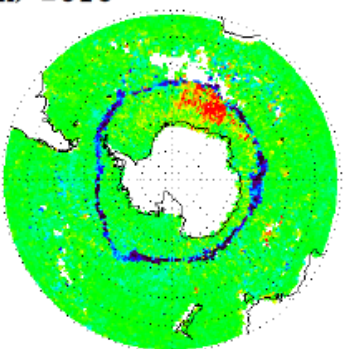

k) 2013

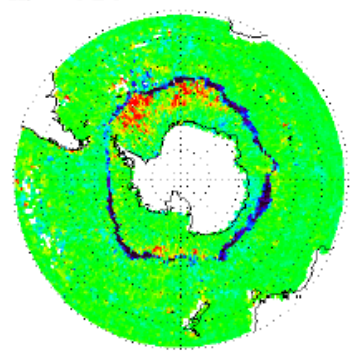

c) 2005

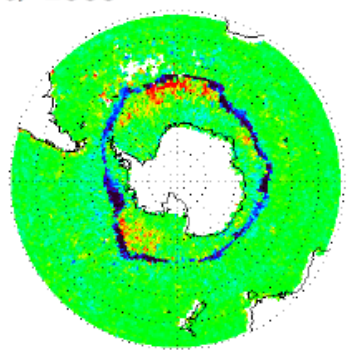

f) 2008

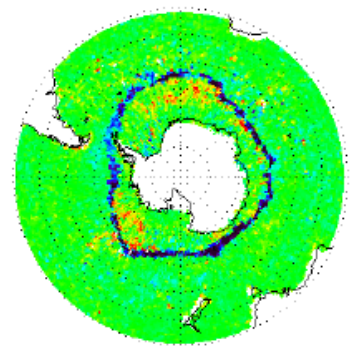

i) 2011

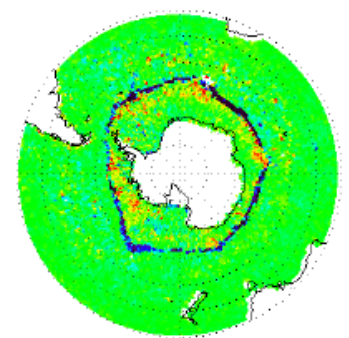

1) 2014

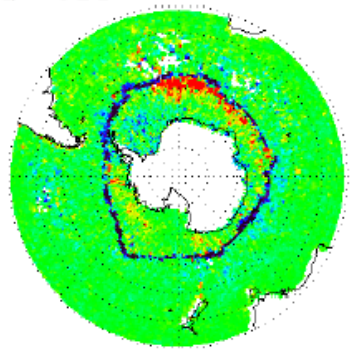

Figure 6. Same as Fig. 5 except for $T_{\text {skin }}\left(\right.$ AO_V$_{-}$) $)$minus $T_{\text {skin }}$ (AA_V6). 


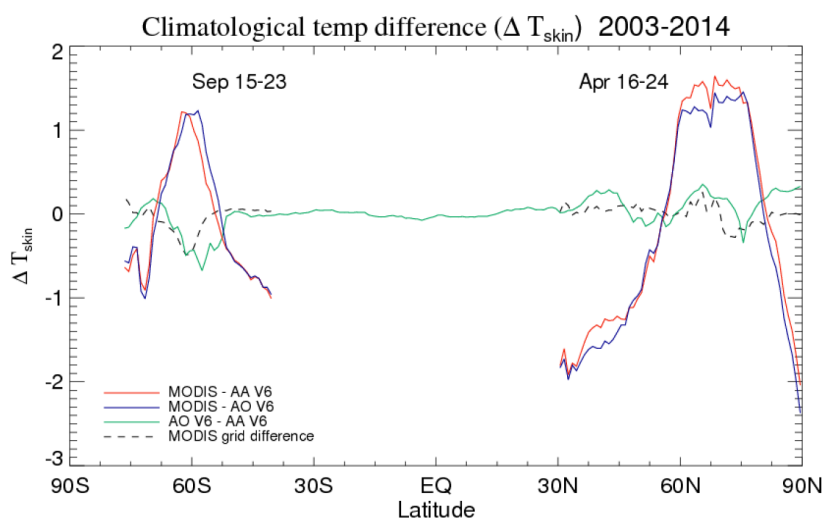

Figure 7. Zonal averaged values of $T_{\text {skin }}$ (MODIS) minus $T_{\text {skin }}$ (AA_V6) (red solid line), $T_{\text {skin }}$ (MODIS) minus $T_{\text {skin }}$ (AO_V6) (blue solid line), and $T_{\text {skin }}$ (AO_V6) minus $T_{\text {skin }}$ (AA_V6) (green solid line). The difference in spatial grid averages of the MODIS data between $4 \mathrm{~km} \times 4 \mathrm{~km}$ and $1^{\circ} \times 1^{\circ}$ is shown by the black dashed line. The difference values are calculated at one degree interval along each latitudinal belt. The climatological data periods are 16-24 April 2003-2014 over the Northern Hemisphere, and 1523 September 2003-2014 over the Southern Hemisphere.

in the other latitudinal zone. It has been noted that the peak of the difference between $T_{\text {skin }}$ (MODIS) and two AIRS data sets in the Northern Hemisphere high-latitude region took place in a broader region than in the Southern Hemisphere. $T_{\text {skin }}$ (MODIS) was up to $1.65 \mathrm{~K}$ higher than the AIRS data sets at the boundaries of the sea ice/water, whereas it was lower by up to $-2.04 \mathrm{~K}$ over the sea ice region. The MODIS IST algorithm was the optimized on the snow/ice surface type, and thus the underestimation of $T_{\text {skin }}$ (MODIS) in the $35-54^{\circ} \mathrm{N}$ and $40-55^{\circ} \mathrm{S}$ may not be unexpected. In general, the overestimation of $T_{\text {skin }}$ (MODIS) to the AIRS retrievals occurred at the sea ice boundary and the underestimation occurred in the sea ice region that can be covered with snow/ice.

The grey solid lines in Fig. A1a-b mean the 5\% significance level of the differences between $T_{\text {skin }}$ (MODIS) and $T_{\text {skin }}\left(\mathrm{AA} \_\mathrm{V} 6\right.$ ), and between $T_{\text {skin }}\left(\mathrm{AO} \_\mathrm{V} 6\right)$ and $T_{\text {skin }}$ (AA_V6) over a possibly frozen region (poleward from $50^{\circ} \mathrm{N}$ and $50^{\circ} \mathrm{S}$, respectively). Based on the $t$ test (von Storch and Zwiers, 1999) at significance level of $p<0.05$, the temperature disagreement between $T_{\text {skin }}$ (MODIS) and $T_{\text {skin }}$ (AA_V6) (red solid line) is significant in 50-55, 58-70, 89$90^{\circ} \mathrm{N}, 50-53$ and $57-62^{\circ} \mathrm{S}$ (Fig. A1a). Considering the uncertainty of MODIS due to the conversion of spatial resolution (black dashed line), the temperature disagreement in 57$62^{\circ} \mathrm{S}$ can become insignificant. However, the discrepancy in $58-70^{\circ} \mathrm{N}$ is significant even if the uncertainty of MODIS is considered. The difference between $T_{\text {skin }}\left(\mathrm{AO}_{-} \mathrm{V} 6\right)$ and $T_{\text {skin }}$ (AA_V6) in $53-60^{\circ} \mathrm{S}$ is significant (Fig. A1b).

The color-coded lines in Fig. 8 interannually represent the differences in temperature among the three data sets for individual years. The thick black lines indicated the yearly dif-

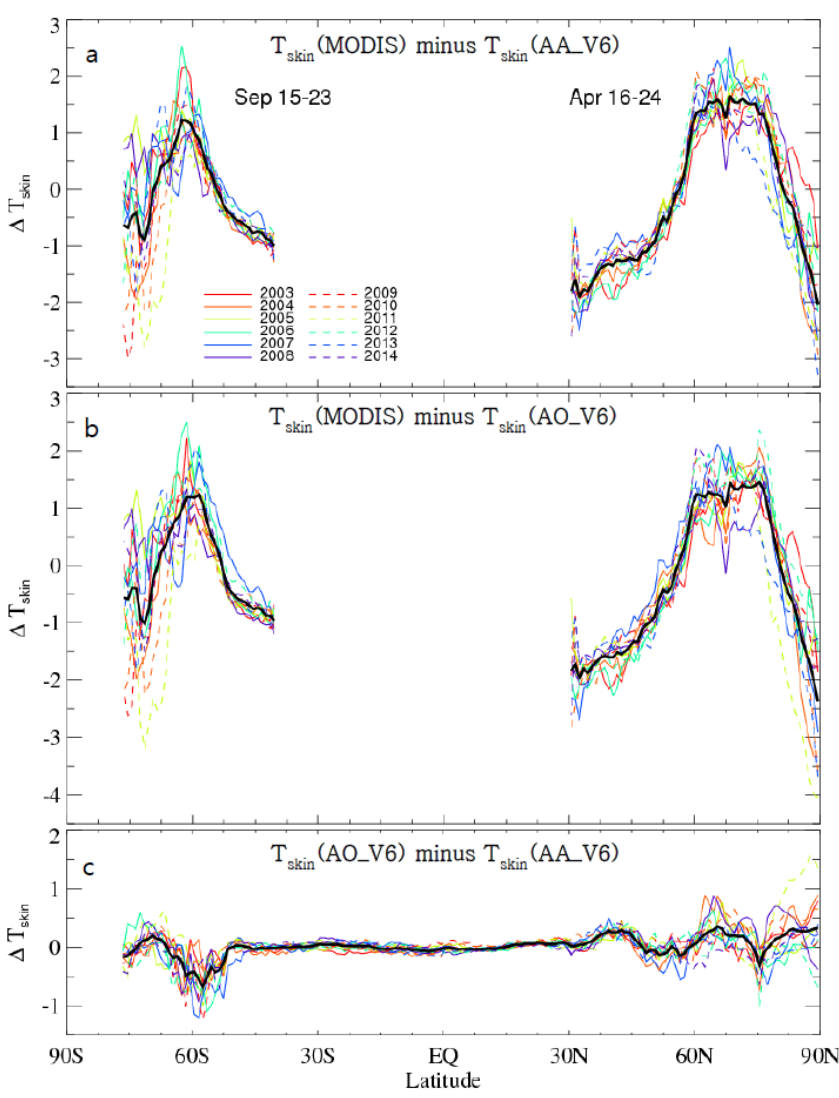

Figure 8. Zonal averaged values of (a) $T_{\text {skin }}$ (MODIS) minus $T_{\text {skin }}\left(\mathrm{AA} \_\mathrm{V} 6\right),(\mathbf{b}) T_{\text {skin }}(\mathrm{MODIS})$ minus $T_{\text {skin }}\left(\mathrm{AO} \_\mathrm{V} 6\right)$, (c) $T_{\text {skin }}$ (AO_V6) minus $T_{\text {skin }}$ (AA_V6) over the Northern Hemisphere from 16 to 24 April 2003-2014, and over the Southern Hemisphere from 15 to 23 September 2003-2014. The values in each year represent the corresponding color lines. The thick black line indicates the mean difference values.

ference averages. There was a significant degree of interannual variation in the difference between $T_{\text {skin }}$ (MODIS) and the two AIRS data sets (Fig. 8a-b). The variation was larger in 2009, 2010 and 2011 over the regions northward of $60^{\circ} \mathrm{N}$ and southward of $55^{\circ} \mathrm{S}$ where sea ice existed. Figure $8 \mathrm{~b}$ shows a value of $T_{\text {skin }}$ (MODIS) minus $T_{\text {skin }}$ (AO_V6) that was similar to that in Fig. 8a. $T_{\text {skin }}$ (MODIS) was lower than $T_{\text {skin }}\left(\mathrm{AO} \_\mathrm{V} 6\right)$ at the ice surface, but higher than $T_{\text {skin }}($ AO_V6) at the boundary of the sea ice. Figure $8 \mathrm{c}$ showed the interannual variation of $T_{\text {skin }}$ (AO_V6) minus $T_{\text {skin }}$ (AA_V6). The interannual variation of the difference between the AIRS retrievals was much larger in the high latitude than in the mid-latitudes. The maximum difference of $1.56 \mathrm{~K}$ between the AIRS retrievals was found at $87-88^{\circ} \mathrm{N}$ in 2011.

There could be several reasons for the observed differences between $T_{\text {skin }}$ (MODIS) and $T_{\text {skin }}$ (AA_V6). The main one can be attributed to the difference in the channel used for the retrievals of the skin temperature. The AIRS/AMSU 
Table 3. The rate of the surface skin temperature change $\left(\mathrm{K} \mathrm{decade}^{-1}\right)$ of the MODIS, AIRS/AMSU, and AIRS only in each $10^{\circ}$ latitudinal belt over the Northern Hemisphere (NH) during 16-24 April and over the Southern Hemisphere (SH) during 15-23 September 2003-2014, using their colocated data in a $1^{\circ} \times 1^{\circ}$ grid. The \pm values define the $95 \%$ confidence intervals for the trends. The symbol " $*$ " means the significant value at a $95 \%$ confidence interval. Note that the rates are subject to large uncertainty due to the short periods of the satellitebased temperature records.

\begin{tabular}{|c|c|c|c|c|c|c|}
\hline $\begin{array}{l}\text { Latitudinal } \\
\text { belt }\end{array}$ & MODIS & AIRS/AMSU & AIRS only & $\begin{array}{l}\text { MODIS minus } \\
\text { AIRS/AMSU }\end{array}$ & $\begin{array}{r}\text { MODIS minus } \\
\text { AIRS only }\end{array}$ & $\begin{array}{r}\text { AIRS only minus } \\
\text { AIRS/AMSU }\end{array}$ \\
\hline \multicolumn{7}{|l|}{$\langle\mathrm{NH}\rangle$} \\
\hline $80-90^{\circ} \mathrm{N}$ & $-0.558 \pm 3.101$ & $-0.100 \pm 3.673$ & $-0.093 \pm 3.736$ & -0.458 & -0.465 & 0.007 \\
\hline $70-80^{\circ} \mathrm{N}$ & $2.302 \pm 1.701^{*}$ & $2.826 \pm 1.878^{*}$ & $2.711 \pm 1.788^{*}$ & -0.524 & -0.409 & -0.115 \\
\hline $60-70^{\circ} \mathrm{N}$ & $-0.506 \pm 1.173$ & $-0.646 \pm 1.294$ & $-0.902 \pm 1.050$ & 0.140 & 0.396 & -0.256 \\
\hline $50-60^{\circ} \mathrm{N}$ & $-0.345 \pm 0.539$ & $-0.522 \pm 0.628$ & $-0.466 \pm 0.550$ & 0.177 & 0.121 & 0.056 \\
\hline $40-50^{\circ} \mathrm{N}$ & $0.292 \pm 0.402$ & $0.103 \pm 0.576$ & $0.191 \pm 0.565$ & 0.189 & 0.101 & 0.088 \\
\hline \multicolumn{7}{|l|}{$<\mathrm{SH}\rangle$} \\
\hline $50-60^{\circ} \mathrm{S}$ & $0.375 \pm 0.400$ & $0.315 \pm 0.466$ & $0.316 \pm 0.600$ & 0.060 & 0.059 & 0.001 \\
\hline $60-70^{\circ} \mathrm{S}$ & $-1.944 \pm 2.271$ & $-1.304 \pm 1.890$ & $-1.300 \pm 1.918$ & -0.640 & -0.644 & 0.004 \\
\hline $70-80^{\circ} \mathrm{S}$ & $-0.769 \pm 2.687$ & $-0.081 \pm 2.586$ & $-0.135 \pm 2.633$ & -0.688 & -0.634 & -0.054 \\
\hline
\end{tabular}

V6 only utilized shortwave window channels for the surface skin temperature, while the MODIS IST algorithm used the longwave window regions. The shortwave window could be mixed with the solar radiation during the daytime, but it was suitable for temperature sounding (Chahine, 1974, 1977; Susskind et al., 2014). The advantage of the longwave window was that its range corresponded to the peak of the infrared radiation emitted from the earth (Prakash, 2000). On the other hand, the longwave window radiation could be affected more by clouds. In order to avoid cloud contamination, the MODIS IST algorithm analyzed the pixel when the MODIS cloud mask was reported as clear sky (Hall et al., 2004). The MODIS cloud mask using visible reflectance had a high accuracy during the daytime, but a lower accuracy during the nighttime due to low illumination. As another reason for the temperature difference, Lee et al. (2013) suggested that there were substantial differences in observation time between MODIS and AIRS in the high latitude regions, since the different scan angles of the two instruments resulted in different footprints, which could lead to the observed difference in temperature. However, we suggested that the surface type classification method could be the primary reason for the temperature difference between the MODIS-based and AIRS-based data sets. AIRS/AMSU SST was retrieved after the surface type was classified. On the other hand, the MODIS IST was calculated without the surface type classification step. Then, the MODIS algorithm categorized pixels being ice if IST was less than the cutoff temperature. MODIS IST was calculated on the snow, sea ice, and ocean, assuming the surface was snow-covered (sea ice). The IST was utilized as a criterion for identifying the ice/water which might cause significant disagreement between the $T_{\text {skin }}$ (MODIS) and $T_{\text {skin }}$ (AA_V6) in the range of $260-273 \mathrm{~K}$.

\section{Comparison of the surface skin temperature trends: IST vs. SST}

In order to further investigate the effects of the difference among the satellite-observed temperatures from different measurement techniques or algorithms on the temperature anomaly trend, we calculated the trend in some latitude belts, using the three satellite-observed temperature data sets at each grid during 16-24 April 2003-2014 (in the Northern Hemisphere) and 15-23 September 2003-2014 in the Southern Hemisphere. During this period, an unusually extensive surface melting event was observed in 2012 (Nghiem et al., 2012; Hall et al., 2013; Comiso and Hall, 2014).

Table 3 shows the temperature anomaly trend with a $95 \%$ confidence level on the $10^{\circ}$ latitude belt. We arranged the data of MODIS IST, AIRS/AMSU, and AIRS only under the same condition in space and time. The significant warming trend in $70-80^{\circ} \mathrm{N}$ was estimated in the following order: AIRS/AMSU $\left(2.83 \mathrm{~K} \mathrm{decade}^{-1}\right)>$ AIRS only $\left(2.71 \mathrm{~K} \mathrm{decade}^{-1}\right)>T_{\text {skin }}$ (MODIS) $\left(2.30 \mathrm{~K} \mathrm{decade}^{-1}\right)$. The warming $\left(0.10\right.$ to $\left.0.38 \mathrm{Kdecade}^{-1}\right)$ at $40-50^{\circ} \mathrm{N}$ and $50-$ $60^{\circ} \mathrm{S}$, and the cooling $\left(-0.08\right.$ to $\left.-1.94 \mathrm{~K} \mathrm{decade}^{-1}\right)$ at $80-$ $90,60-70,50-60^{\circ} \mathrm{N}, 60-70$ and $70-80^{\circ} \mathrm{S}$ of the three data sets occurred, but the trends were not significant. Comiso and Hall (2014) reported the SST trend using the Goddard Institute for Space Studies (GISS) data set as $0.60 \mathrm{Kdecade}^{-1}$ and the trend using the Advanced Very High Resolution Radiometer (AVHRR) data set as $0.69 \mathrm{~K} \mathrm{decade}^{-1}$ in the Arctic $\left(>64^{\circ} \mathrm{N}\right)$ during $1981-2012$. Our result in $70-80^{\circ} \mathrm{N}$, compared with the above studies, seems to indicate an acceleration in the Arctic warming.

The warming trend in the northern hemispheric high latitudes had been known to be caused in part by the wellknown positive feedback among snow/ice, surface albedo 
and temperature (Curry et al., 1995; Comiso and Hall, 2014). $T_{\text {skin }}$ (MODIS) had a greater cooling tendency compared to $T_{\text {skin }}\left(\mathrm{AA} \_\right.$V6) in the higher latitude regions (70$90^{\circ} \mathrm{N}$ and $60-80^{\circ} \mathrm{S}$ ) (Table 3). The trend difference between the two temperatures was $-0.69 \mathrm{Kdecade}^{-1}$ at 70 $80^{\circ} \mathrm{S}$. The trend difference of the $T_{\text {skin }}\left(\mathrm{AA} \_\mathrm{V} 6\right)$ and $T_{\text {skin }}$ (AO_V6) (i.e., AIRS only minus AIRS/AMSU) was the largest $\left(-0.26 \mathrm{~K} \mathrm{decade}^{-1}\right)$ at $60-70^{\circ} \mathrm{N}$. The cooling trend $\left(-0.90 \mathrm{~K} \mathrm{decade}^{-1}\right)$ of the $T_{\text {skin }}\left(\mathrm{AO} \_\mathrm{V} 6\right)$ was greater than that $\left(-0.65 \mathrm{Kdecade}^{-1}\right)$ of $T_{\text {skin }}\left(\mathrm{AA} \_\mathrm{V} 6\right)$ at the latitude band.

Figure 9a-b showed the SST anomaly trends from the $T_{\text {skin }}$ (MODIS) in a $1^{\circ} \times 1^{\circ}$ grid over the Northern Hemisphere during 16-24 April 2003-2014 and over the Southern Hemisphere during 15-23 September 2003-2014. The $T_{\text {skin }}$ (MODIS) trend was calculated on the grid, which had available data that existed for over 10 years. Figure $9 \mathrm{c}-\mathrm{d}$ and $\mathrm{e}-\mathrm{f}$ showed the trend data for $T_{\text {skin }}\left(\mathrm{AA} \_\mathrm{V} 6\right)$ and $T_{\text {skin }}\left(\mathrm{AO}_{-} \mathrm{V} 6\right.$ ), respectively, which all had 12-year data, individually. The trend distributions in all three of the data sets were similar over the Northern Hemisphere. Warming trend in the Beaufort Sea, East Siberian Sea and Kara Sea was detected, while cooling was observed in the Hudson Bay and near Greenland. The significant warming trend appeared at $70-80^{\circ} \mathrm{N}$ as shown in Table 3, and the trend based on the spatial distribution varied depending on the regions (Fig. 9a, c and e). According to Comiso and Hall (2014), a strong warming trend $\left(>1.5 \mathrm{~K} \mathrm{decade}^{-1}\right.$ ) existed near the Kara Sea and Baffin Bay among the entire Arctic, consistent with the noticeable trend revealed near the Kara Sea in our study. Over the Southern Hemisphere, there were not enough data to derive a trend for $T_{\text {skin }}$ (MODIS) mostly due to clouds. The trend analysis over the sea ice regions from $T_{\text {skin }}\left(\mathrm{AA} \_\mathrm{V} 6\right)$ and $T_{\text {skin }}\left(\mathrm{AO} \_\mathrm{V} 6\right)$ showed a strong cooling trend, especially near the Antarctic peninsula between the Weddell and Ross Seas (Fig. 9d and f). The cooling trend was generally dominant over the Southern Hemisphere. Marshall et al. (2014) suggested that based on the model experiments, the cooling trend around Antarctica as opposed to the warming trend around the Arctic Ocean was the result of the offset between the greenhouse gas and ozone hole responses, emphasizing the larger cooling effects associated with the Antarctic ozone hole.

The 12-year mean of the $T_{\text {skin }}$ (MODIS) minus $T_{\text {skin }}$ (AA_V6) (Fig. 10a and c) and of the trend difference between $T_{\text {skin }}$ (MODIS) and $T_{\text {skin }}$ (AA_V6) (Fig. 10b and d) were compared in order to reveal the relationship between the temperature difference and the corresponding trend difference over the Northern Hemisphere during 16-24 April 2003-2014 and over the Southern Hemisphere during 1523 September 2003-2014. $T_{\text {skin }}$ (MODIS) was higher than $T_{\text {skin }}$ (AA_V6) over the bays of Hudson and Baffin, and Bering Sea (Fig. 10a). The warming trend of the $T_{\text {skin }}$ (MODIS) was also greater than that of the $T_{\text {skin }}$ (AA_V6) over the Hudson Bay and near the Kara Sea (Fig. 10b). The data for the trend difference in the Southern Hemisphere was

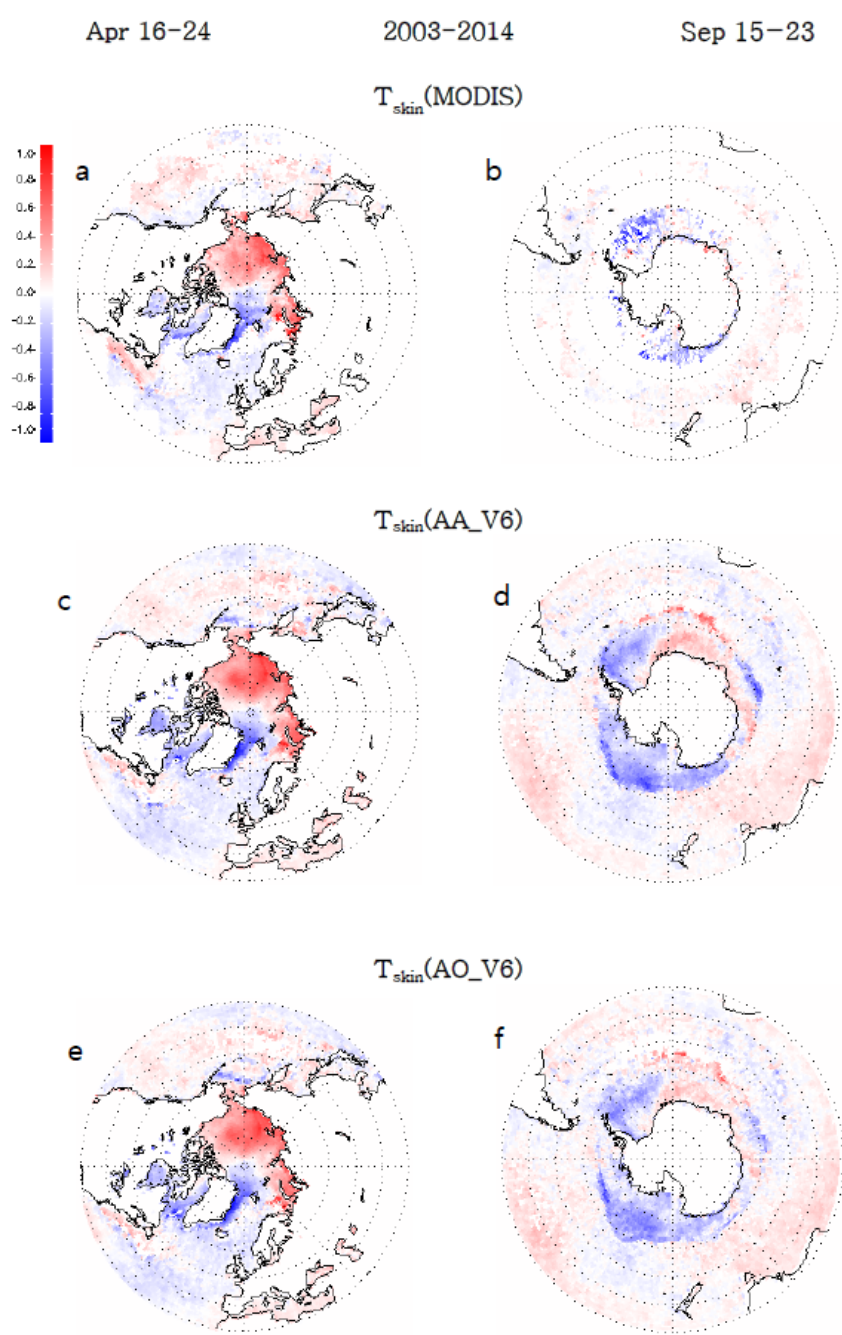

Figure 9. Satellite-derived 9-day anomaly trends $\left(\mathrm{K} \mathrm{yr}^{-1}\right)$ in a grid box of $1^{\circ} \times 1^{\circ}$ over the Northern Hemisphere during 16-24 April 2003-2014, for the (a) $T_{\text {skin }}$ (MODIS), (c) $T_{\text {skin }}$ (AA_V6), and (e) $T_{\text {skin }}($ AO_V6), and over the Southern Hemisphere during 1624 September 2003-2014, for the (b) $T_{\text {skin }}$ (MODIS), (d) $T_{\text {skin }}$ (AA_V6), and (f) $T_{\text {skin }}($ AO_V6).

not sufficient due to the missing data of $T_{\text {skin }}$ (MODIS) in the cloudy condition (Fig. 10d).

Figure 11 showed over both hemispheres the 12-year mean of the $T_{\text {skin }}\left(\mathrm{AO} \_\mathrm{V} 6\right)$ minus $T_{\text {skin }}\left(\mathrm{AA} \_\mathrm{V} 6\right)$ (Fig. 11a and c) and the corresponding trend difference of the $T_{\text {skin }}\left(\mathrm{AO}_{-} \mathrm{V} 6\right)$ and $T_{\text {skin }}$ (AA_V6) (Fig. 11b and d). The relationship of the temperature difference and trend difference over the Southern Hemisphere in Fig. 10 was hard to analyze due to the absence of a $T_{\text {skin }}$ (MODIS) trend (Fig. 10c-d). However, Fig. 11c-d clearly showed that the temperature difference had a significant impact on the trend difference over the Southern Hemisphere. The trend of the $T_{\text {skin }}$ (AA_V6) and $T_{\text {skin }}\left(\mathrm{AO} \_\mathrm{V} 6\right)$ agreed well except for at the region of the sea 

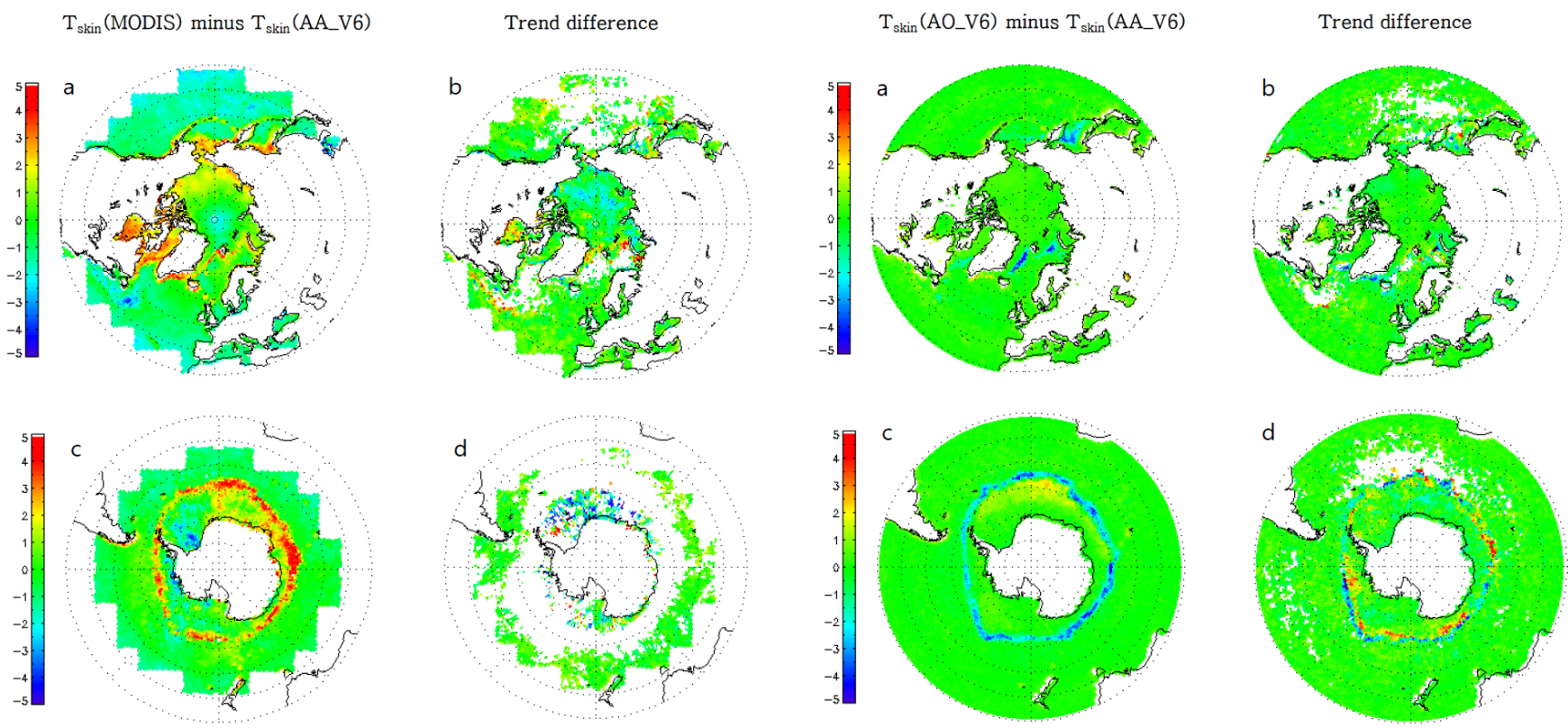

Figure 10. (a) 12-year mean of $T_{\text {skin }}$ (MODIS) minus $T_{\text {skin }}$ (AA_V6) (K) over the Northern Hemisphere during 16-24 April 2003-2014, and (b) difference in the thermal trend $\left(\mathrm{K} \mathrm{decade}^{-1}\right)$ between $T_{\text {skin }}$ (MODIS) and $T_{\text {skin }}$ (AA_V6). (c)-(d) are the same as (a)-(b) except for over the Southern Hemisphere during 1624 September 2003-2014, respectively. (a) is the same as Fig. 3a in Kang and Yoo (2015).

ice boundary, implying that the algorithm identifying the sea ice affected the SST trend.

Uncertainties among satellite observations ( $T_{\text {skin }}$ (MODIS), $T_{\text {skin }}$ (AA_V6), and $T_{\text {skin }}($ AO_V6)) in the sea ice region of the Northern Hemisphere are generally similar to those of the Southern Hemisphere in terms of zonal averages. However, the systematic difference between the observations can be more clearly seen in the latter region than in the former region due to more oceanic regions in the Southern Hemisphere (Figs. 10-11, and see also Fig. 7).

Table 4 quantitatively showed how the temperature differences among the three types of SST affected each trend difference over the hemispheric regions poleward either from $50^{\circ} \mathrm{N}$ (shown in the left side of the table) during 16-24 April 2003-2014 or from $50^{\circ} \mathrm{S}$ during 15-23 September 20032014. In the upper portion, the average of the temperature difference and the trend difference in the grid corresponding to the temperature difference condition was used, whereas the average values on the grids that had the same signs for the temperature difference and the trend difference were used in the lower portion. Only the cases where grid number was greater than 100 were considered. The warmer temperature led to relatively warming trend, the cooler temperature led to relatively cooling trend. When the $T_{\text {skin }}$ (MODIS) was greater than $T_{\text {skin }}$ (AA_V6) in the regions poleward from $50^{\circ} \mathrm{S}$, the trend difference was in the reduced

Figure 11. Same as Fig. 10 except for $T_{\text {skin }}\left(A_{-}\right.$V6) minus $T_{\text {skin }}$ (AA_V6). (a) is the same as Fig. 3c in Kang and Yoo (2015).

cooling trend (i.e., warmer direction) as $-0.96,-0.66$, and $-0.21 \mathrm{~K} \mathrm{decade}^{-1}$ with the conditions of $T_{\text {skin }}$ (MODIS) minus $T_{\text {skin }}$ (AA_V6) rising as more than $1,1.5$, and $2 \mathrm{~K}$, respectively. The uncertainty of the satellite-derived temperatures had a substantial effect on the uncertainty of the temperature trends. The data set has been reduced in the lower section of Table 4 . The sample size can affect the estimated impact of $\Delta \mathrm{T}$ on $\Delta \mathrm{Trend}$, but it looks like that the impact on the trends in the lower section is almost consistent with that in the upper section despite the reduced sample sizes.

\section{Conclusions}

The satellite-derived L3 products of MODIS IST and two SSTs from AIRS/AMSU and AIRS only were investigated with a comparative analysis during the vernal periods of 2003-2014: 16-24 April over the Northern Hemisphere and 15-23 September over the Southern Hemisphere. The original MODIS IST data were regridded onto a $1^{\circ} \times 1^{\circ}$ grid box for comparison with the AIRS retrievals. The difference between the original MODIS IST and the converted one was within $0.5 \mathrm{~K}$ in a latitudinal belt.

The differences among the three types of satellite derived SST data were most prominent over the sea ice regions. $T_{\text {skin }}$ (MODIS) and $T_{\text {skin }}($ AA_V6) were comparable $(r=0.97$ $0.99)$, but there was systematic disagreement occurred in the $T_{\text {skin }}$ (MODIS) range of 260-273 K. The southern hemispheric high latitude $\left(60-90^{\circ} \mathrm{S}\right)$ was the primary contributor to the disagreement between them. In comparison with the $T_{\text {skin }}$ (AA_V6) in a latitudinal belt, the $T_{\text {skin }}$ (MODIS) was 
Table 4. Uncertainties of the satellite-derived surface skin temperature rate (or trend; $\Delta$ Trend) due to the temperature difference ( $\Delta T_{\text {skin }}$ ) for the cases of $T_{\text {skin }}$ (MODIS) minus $T_{\text {skin }}\left(\right.$ AA_V6) and $T_{\text {skin }}\left(A_{-}\right.$_V6) minus $T_{\text {skin }}$ (AA_V6) in the upper portion of the table. Also, the values of uncertainties provided in the lower portion of the table indicate the cases of $\pm \Delta$ Trend with respect to $\pm \Delta T_{\text {skin }}$ (double signs in the same order). The uncertainties are not shown when the number of the grid $\left(1^{\circ} \times 1^{\circ}\right)$ points (i.e., No. of grids in the table) is less than 100 .

\begin{tabular}{|c|c|c|c|c|c|c|c|c|c|c|c|c|}
\hline \multirow[t]{3}{*}{$\Delta T_{\text {skin }}(\mathrm{K})$} & \multicolumn{6}{|c|}{ Poleward from $50^{\circ} \mathrm{N}$} & \multicolumn{6}{|c|}{ Poleward from $50^{\circ} \mathrm{S}$} \\
\hline & \multicolumn{3}{|c|}{$T_{\text {skin }}(\mathrm{MODIS})$ vs. $T_{\text {skin }}\left(\mathrm{AA} \_\mathrm{V} 6\right)$} & \multicolumn{3}{|c|}{$T_{\text {skin }}\left(\mathrm{AO} \_\mathrm{V} 6\right)$ vs. $T_{\text {skin }}\left(\mathrm{AA} \_\mathrm{V} 6\right)$} & \multicolumn{3}{|c|}{$T_{\text {skin }}(\mathrm{MODIS})$ vs. $T_{\text {skin }}\left(\mathrm{AA} \_\mathrm{V} 6\right)$} & \multicolumn{3}{|c|}{$T_{\text {skin }}\left(\mathrm{AO} \_\mathrm{V} 6\right)$ vs. $T_{\text {skin }}\left(\mathrm{AA} \_\mathrm{V} 6\right)$} \\
\hline & $\begin{array}{r}\text { No. of } \\
\text { grids }\end{array}$ & $\Delta T_{\text {skin }}$ & $\begin{array}{r}\Delta \text { Trend } \\
\left(\mathrm{Kdecade}^{-1}\right)\end{array}$ & $\begin{array}{r}\text { No. of } \\
\text { grids }\end{array}$ & $\Delta T_{\text {skin }}$ & $\begin{array}{r}\Delta \text { Trend } \\
\left(\mathrm{Kdecade}^{-1}\right)\end{array}$ & $\begin{array}{r}\text { No. of } \\
\text { grids }\end{array}$ & $\Delta T_{\text {skin }}$ & $\begin{array}{r}\Delta \text { Trend } \\
\left(\mathrm{K} \mathrm{decade}^{-1}\right)\end{array}$ & $\begin{array}{r}\text { No. of } \\
\text { grids }\end{array}$ & $\Delta T_{\text {skin }}$ & $\begin{array}{r}\Delta \text { Trend } \\
\left(\mathrm{Kdecade}^{-1}\right)\end{array}$ \\
\hline$\geq 1.0$ & 2155 & 2.01 & -0.10 & 95 & - & - & 425 & 2.01 & -0.96 & 378 & 1.37 & 0.03 \\
\hline$\geq 1.5$ & 1506 & 2.34 & 0.04 & 19 & - & - & 253 & 2.25 & -0.66 & 104 & 1.80 & 0.24 \\
\hline$\geq 2.0$ & 940 & 2.71 & 0.19 & 5 & - & - & 134 & 2.69 & -0.21 & 22 & - & - \\
\hline$\leq-1.0$ & 1839 & -1.59 & -0.45 & 236 & -2.25 & -0.34 & 224 & -1.71 & -0.43 & 877 & -2.19 & -0.37 \\
\hline$\leq-1.5$ & 921 & -1.94 & -0.45 & 162 & -2.72 & -0.47 & 115 & -2.18 & -0.16 & 654 & -2.52 & -0.55 \\
\hline$\leq-2.0$ & 367 & -2.27 & -0.60 & 109 & -3.20 & -0.78 & 55 & - & - & 472 & -2.82 & -0.69 \\
\hline$\geq 1.0$ & 912 & 2.15 & 1.21 & 40 & - & - & 139 & 2.09 & 1.36 & 179 & 1.40 & 1.01 \\
\hline$\geq 1.5$ & 707 & 2.41 & 1.22 & 8 & - & - & 94 & - & - & 51 & - & - \\
\hline$\geq 2.0$ & 499 & 2.70 & 1.22 & 1 & - & - & 64 & - & - & 15 & - & - \\
\hline$\leq-1.0$ & 1309 & -1.59 & -0.90 & 126 & -2.51 & -2.02 & 122 & -1.69 & -2.42 & 500 & -2.26 & -1.96 \\
\hline$\leq-1.5$ & 643 & -1.96 & -0.92 & 89 & - & - & 61 & - & - & 387 & -2.55 & -2.06 \\
\hline$\leq-2.0$ & 272 & -2.28 & -1.02 & 69 & - & - & 27 & - & - & 293 & -2.81 & -2.06 \\
\hline
\end{tabular}

higher by up to $1.65 \mathrm{~K}$ than $T_{\text {skin }}$ (AA_V6) on the boundary of the sea ice/water, whereas it was lower by up to $-2.04 \mathrm{~K}$ in the sea ice region.

The spatial correlation coefficients (0.992-0.999) of the $T_{\text {skin }}\left(\right.$ AO_V6) and $T_{\text {skin }}\left(\mathrm{AA} \_\right.$V6) over both hemispheres were greater than those $(0.968-0.994)$ between $T_{\text {skin }}$ (MODIS) and $T_{\text {skin }}\left(\mathrm{AA} \_\mathrm{V} 6\right)$. The $T_{\text {skin }}\left(\mathrm{AO} \_\mathrm{V} 6\right)$ compared to the $T_{\text {skin }}$ (AA_V6) had a bias of $0.168 \mathrm{~K}$ with a RMSE of $0.590 \mathrm{~K}$ over the Northern Hemisphere high latitudes and a bias of $-0.109 \mathrm{~K}$ with a RMSE of $0.852 \mathrm{~K}$ over the southern hemispheric high latitudes. There was a systematic disagreement between the $T_{\text {skin }}\left(\mathrm{AA} \_\mathrm{V} 6\right)$ and $T_{\text {skin }}\left(\mathrm{AO} \_\mathrm{V} 6\right)$ at the sea ice boundary. It is likely due to the fact that the AIRS only algorithm utilized a less accurate GCM forecast than the microwave data over the seasonally varying frozen oceans.

The temperature differences among the three types of data sets showed a high degree of interannual variations over the latitudinal belts where sea ice existed. The significant warming rates $\left(2.3 \pm 1.7 \sim 2.8 \pm 1.9 \mathrm{~K} \mathrm{decade}^{-1}\right)$ were revealed by all three data sets in the northern hemispheric highlatitude regions $\left(70-80^{\circ} \mathrm{N}\right)$ could be interpreted as the icealbedo feedback. The discrepancies between the trends of the $T_{\text {skin }}\left(\mathrm{AA} \_\mathrm{V} 6\right)$ and $T_{\text {skin }}\left(\mathrm{AO} \_\mathrm{V} 6\right)$ occurred at the sea ice boundary. When the $T_{\text {skin }}$ (AA_V6) trends were compared to those of the $T_{\text {skin }}$ (MODIS) or $T_{\text {skin }}\left(\right.$ AO_V6) in a $1^{\circ} \times 1^{\circ}$ grid, the warmer temperature difference tended to lead to a relative warming trend, whereas the cooler temperature difference tended to lead to a relative cooling trend.

The systematic disagreement between the $T_{\text {skin }}$ (MODIS) and $T_{\text {skin }}$ (AA_V6) could be caused by (1) the channels used for the surface skin temperature, (2) the cloud contamination, (3) the difference in local time of observation between the MODIS and AIRS, and (4) the surface type classification method. Whereas the AIRS/AMSU V6 used only the shortwave window channels for the surface skin temperature, MODIS IST used the longwave window regions. The MODIS IST product utilized the MODIS cloud mask with visible reflectance, which had lower accuracy during the night (Hall et al., 2004). Lee et al. (2013) reported that the local times of observation between the MODIS and AIRS were almost the same from $60^{\circ} \mathrm{N}-60^{\circ} \mathrm{S}$, but they were quite different in the high latitude regions. It is likely that the main cause to the observed SST differences near the sea ice boundary was in the way the surface type was classified. The AIRS/AMSU algorithm conjugated the emissivity difference in the low and high frequency microwave bands (23 and $50 \mathrm{GHz}$ ) in order to identify sea ice. However, MODIS IST was calculated without the surface type classification.

The AIRS/AMSU L2 data offer the surface type (coastline, land, ocean, two types of sea ice, two types of snow, and glacier/snow), and the AIRS/AMSU L3 data provide the number of these various surface types in a grid. The AIRS only L2 also offer the surface type (coastline, land, ocean, two types of sea ice, and snow), and its L3 data provide the number of these various surface types in a grid. Under the condition without ground truth, the direct validation has a limit because the surface classifications of AIRS/AMSU and AIRS only have some difference. Although the AIRS only has utilized the forecast surface temperature from the GFS, there is a good agreement in SST between AIRS/AMSU and AIRS only in most regions. However, the disagreement between them over the land regions of the Sahara desert, parts of Spain and in the US with snow cover at night has been reported (Dang et al., 2012).

We have investigated the effect in the difference of spatial resolution between $\mathrm{L} 2$ and $\mathrm{L} 3$ products, utilizing the L2 products ( $T_{\text {skin }}$ (MODIS), $T_{\text {skin }}\left(\mathrm{AA} \_\mathrm{V} 6\right)$, and $T_{\text {skin }}$ (AO_V6)) for a year of 2003. Overall the uncertainties 
among the three L2 data sets are similar to those of the L3, but the magnitude of $T_{\text {skin }}$ (MODIS) minus $T_{\text {skin }}\left(\mathrm{AA} \_\mathrm{V} 6\right.$ ) for L2 data sets is somewhat different from that for the L3 data sets (not shown). Based on the L3 products in this study, it seems to be sufficient to allow us to show the systematic characteristics of the uncertainties. Although the detailed analysis of L2 is beyond the scope of this study, further studies are warranted.

The SST in the polar region is a useful parameter being used to derive the climate change signal, although it has been challenging to measure an accurate SST. Based on our results from detailed comparative investigation, we cautiously suggested that the observed difference and uncertainty among the satellite-derived SSTs were likely caused by the different sea ice detecting methods used in each algorithm. This study suggested that the ice forecast derived from other microwave satellite data could improve the AIRS only product from the better accuracy of surface classification. In addition, the methods also affected the temperature trend. In this study, we aimed to help in understanding characteristics of the infrared and microwave measurements for the surface skin temperature, and the method for identifying sea ice. We believe the results of this study can be useful for the interpretation and the modeling of the climate change associated with the temperature trends. 
Appendix A:

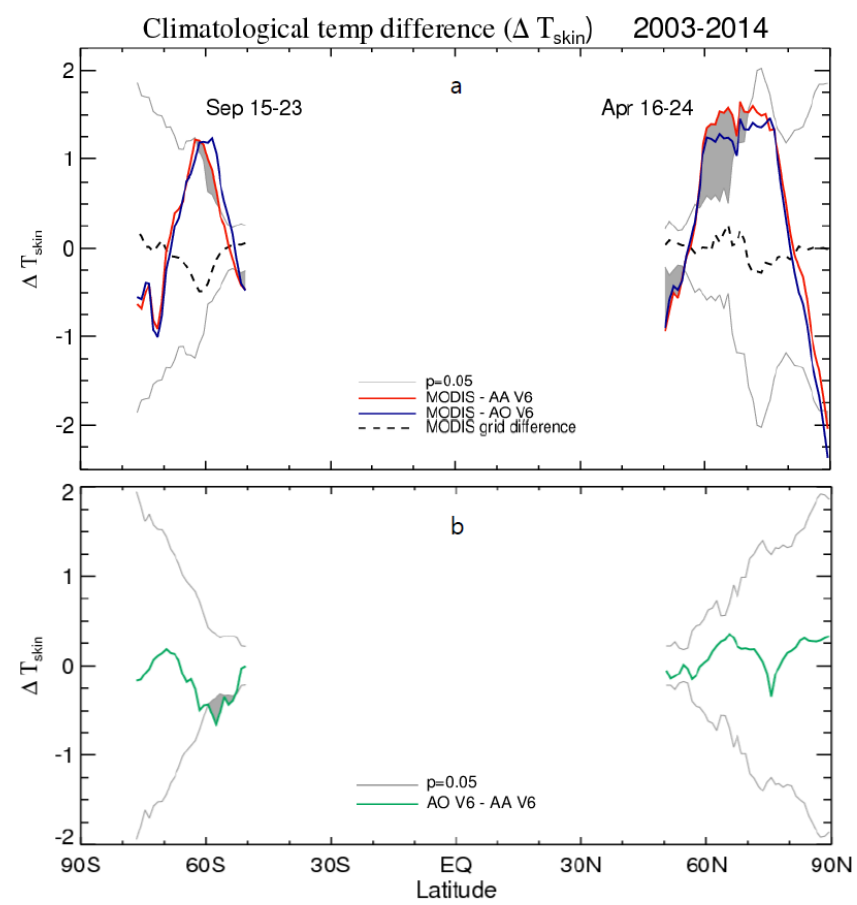

Figure A1. The difference values (a) between $T_{\text {skin }}$ (MODIS) and $T_{\text {skin }}$ (AA_V6), and (b) $T_{\text {skin }}\left(\right.$ AA_V6) and $T_{\text {skin }}($ AO_V6) over a possibly frozen region; shown in Fig. 7. The $5 \%$ significance level is presented as grey solid lines, and the shaded areas are statistically significant at the 0.05 level. 
Acknowledgements. This study was supported by the National Research Foundation of Korea (NRF) grant funded by the Korean Government (MSIP) (No. 2009-0083527) and the Korean Ministry of Environment as the Eco-technopia 21 project (No. 2012000160003). We thank Goddard Earth Sciences Data Information and Services Center for AIRS/AMSU data, and NASA National Snow and Ice Data Center for MODIS IST data. We also thank Bob Iacovazzi Jr., J. M. Blaisdell, and C.-Y. Liu for their constructive comments.

Edited by: B. Kahn

\section{References}

Aumann, H. H., Chahine, M. T., Gautier, C., Goldberg, M. D., Kalnay, E., McMillin, L. M., Revercomb, H., Rosenkranz, P. W., Smith, W. L., Staelin, D. H., Strow, L. L., and Susskind, J.: AIRS/AMSU/HSB on the Aqua mission: Design, science objectives, data products, and processing systems, IEEE IEEE T. Geosci. Remote, 41, 253-264, doi:10.1109/tgrs.2002.808356, 2003.

Barnes, W. L., Pagano, T. S., and Salomonson, V. V.: Prelaunch characteristics of the Moderate resolution Imaging Spectroradiometer (MODIS) on EOS-AM1, IEEE T. Geosci. Remote, 36, 1088-1100, doi:10.1109/36.700993, 1998.

Boucher, O., Randall, D., Artaxo, P., Bretherton, C., Feingold, G., Forster, P., Kerminen, V.-M., Kondo, Y., Liao, H., Lohmann, U., Rasch, P., Satheesh, S. K., Sherwood, S., Stevens, B., and Zhang, X. Y.: Clouds and Aerosols, in: Climate change 2013: The physical science basis, Contribution of working group I to the fifth assessment report of the intergovernmental panel on climate change, edited by: Stocker, T. F., Qin, D., Plattner, G.-K., Tignor, M., Allen, S. K., Boschung, J., Nauels, A., Xia, Y., Bex, V., and Midgley, P. M., Cambridge University Press, Cambridge, UK, 571-657, 2013.

Chahine, M. T.: Remote sounding of cloudy atmospheres. I. The single cloud layer, J. Atmos. Sci., 31, 233-243, doi:10.1175/1520-0469(1974)031<0233:RSOCAI>2.0.CO;2, 1974.

Chahine, M. T.: Remote sounding of cloudy atmospheres. II. Multiple cloud formations, J. Atmos. Sci., 34, 744-757, doi:10.1175/1520-0469(1977)034<0744:RSOCAI>2.0.CO;2, 1977.

Comiso, J. C. and Hall, D. K.: Climate trends in the Arctic as observed from space, Wiley Interdiscip. Rev.-Clim. Chang., 5, 389409, doi:10.1002/wcc.277, 2014.

Comiso, J. C. and Stock, L. V.: Studies of Antarctic cloud cover variability from 1982 through 1999, Geoscience and Remote Sensing Symposium, 2001, IGARSS '01, IEEE 2001 International, 1782-1785, 2001.

Curry, J. A., Schramm, J. L., and Ebert, E. E.: Sea icealbedo climate feedback mechanism, J. Clim., 8, 240-247, doi:10.1175/1520-0442(1995)008<0240:SIACFM>2.0.CO;2, 1995.

Dang, H. V. T., Lambrigtsen, B., and Manning, E.: AIRS/AMSU/HSB version 6 level 2 performance and test report, available at: http://disc.sci.gsfc.nasa.gov/AIRS/documentation/
v6_docs/v6releasedocs-1/V6_L2_Performance_and_Test_ Report.pdf (last access: 8 June 2015), 2012.

Dong, S. F., Gille, S. T., Sprintall, J., and Gentemann, C.: Validation of the Advanced Microwave Scanning Radiometer for the Earth Observing System (AMSR-E) sea surface temperature in the southern ocean, J. Geophys. Res.-Oceans, 111, C04002, doi:10.1029/2005jc002934, 2006.

Donlon, C. J., Minnett, P. J., Gentemann, C., Nightingale, T. J., Barton, I. J., Ward, B., and Murray, M. J.: Toward improved validation of satellite sea surface skin temperature measurements for climate research, J. Clim., 15, 353-369, doi:10.1175/15200442(2002)015<0353:tivoss>2.0.co;2, 2002.

Emery, W. J., Castro, S., Wick, G. A., Schluessel, P., and Donlon, C.: Estimating sea surface temperature from infrared satellite and in situ temperature data, Bull. Amer. Meteorol. Soc., 82, 27732785, doi:10.1175/1520-0477(2001)082<2773:esstfi>2.3.co;2, 2001.

Gardner, M. W. and Dorling, S. R.: Artificial neural networks (the multilayer perceptron) - A review of applications in the atmospheric sciences, Atmos. Environ., 32, 2627-2636, doi:10.1016/s1352-2310(97)00447-0, 1998.

Grody, N., Weng, F., and Ferraro, R.: Application of AMSU for obtaining water vapor, cloud liquid water, precipitation, snow cover and sea ice concentration, in: Technical proceedings of the tenth international atovs study conference, Colorado, USA, 27 January-2 February 1999, 230-240, 1999.

Hall, D. K. and Riggs, G. A.: Accuracy assessment of the MODIS snow products, Hydrol. Process., 21, 1534-1547, doi:10.1002/hyp.6715, 2007.

Hall, D. K. and Riggs, G. A.: MODIS/Terra Sea Ice Extent and IST Daily L3 Global 4 km EASE-Grid Day, Version 6, Subset used: 16-24 April and 15-23 September 2003-2015, Boulder, Colorado, USA, NASA DAAC at the National Snow and Ice Data Center, available at: http://nsidc.org/data/docs/daac/modis/ mod29e1d/index.html (updated daily), last access: 29 June, 2015.

Hall, D. K., Key, J. R., Casey, K. A., Riggs, G. A., and Cavalieri, D. J.: Sea ice surface temperature product from MODIS, IEEE T. Geosci. Remote, 42, 1076-1087, doi:10.1109/tgrs.2004.825587, 2004.

Hall, D. K., Comiso, J. C., DiGirolamo, N. E., Shuman, C. A., Box, J. E., and Koenig, L. S.: Variability in the surface temperature and melt extent of the Greenland ice sheet from MODIS, Geophys. Res. Lett., 40, 2114-2120, doi:10.1002/grl.50240, 2013.

Hewison, T. J. and English, S. J.: Airborne retrievals of snow and ice surface emissivity at millimeter wavelengths, IEEE T. Geosci. Remote, 37, 1871-1879, doi:10.1109/36.774700, 1999.

Jakob, C.: Cloud cover in the ECMWF reanalysis, J. Clim., 12, 947959, doi:10.1175/1520-0442(1999)012<0947:cciter>2.0.co;2, 1999.

Jin, M., Dickinson, R. E., and Vogelmann, A. M.: A comparison of CCM2-BATS skin temperature and surface-air temperature with satellite and surface observations, J. Clim., 10, 1505-1524, doi:10.1175/1520-0442(1997)010<1505:ACOCBS>2.0.CO;2, 1997.

Kang, H.-J. and Yoo, J.-M.: Uncertainties of satellite-observed surface skin temperatures due to sea ice in the Arctic ocean: MODIS, AIRS/AMSU and AIRS Only, J. Korean Earth Sci. Soc., 36, 139-157, doi:10.5467/JKESS.2015.36.2.139, 2015 (in Korean). 
Key, J. R., Collins, J. B., Fowler, C., and Stone, R. S.: Highlatitude surface temperature estimates from thermal satellite data, Remote Sens. Environ., 61, 302-309, doi:10.1016/S00344257(97)89497-7, 1997.

Knuteson, R., Cychosz, J., Lee, S. C., Revercomb, H., Tobin, D., and Vinson, K.: Comparison of LST from AIRS and MODIS from the EOS Aqua platform, 10th symposium on Integrated Observing and Assimilation Systems for the Atmosphere, Oceans, and Land Surface (IOASAOLS), the 86th AMS annual meeting, Atlanta, USA, 28 January-3 February 2006, P2.2, 2006.

Kongoli, C., Boukabara, S., Yan, B., Weng, F., and Ferraro, R.: Sea ice concentration retrievals from variationally retrieved microwave surface emissivities, available at: http://microrad2008. cetem.org/public/presentations/20080314_16.50_Kongoli.pdf (last access: 4 December 2014), 2008.

Lachlan-Cope, T.: Antarctic clouds, Polar Res., 29, 150-158, doi:10.1111/j.1751-8369.2010.00148.x, 2010.

Lee, Y.-R., Yoo, J.-M., Jeong, M.-J., Won, Y.-I., Hearty, T., and Shin, D.-B.: Comparison between MODIS and AIRS/AMSU satellite-derived surface skin temperatures, Atmos. Meas. Tech., 6, 445-455, doi:10.5194/amt-6-445-2013, 2013.

Li, J., Liu, C. Y., Zhang, P., and Schmit, T. J.: Applications of full spatial resolution space-based advanced infrared soundings in the preconvection environment, Wea. Forecasting, 27, 515-524, doi:10.1175/WAF-D-10-05057.1, 2012.

Liou, K. N.: An introduction to atmospheric radiation, Academic Press, Amsterdam; Boston, 583 pp., 2002.

Liu, C. Y., Li, J., Weisz, E., Schmit, T. J., Ackerman, S. A., and Huang, H. L.: Synergistic use of AIRS and MODIS radiance measurements for atmospheric profiling, Geophys. Res. Lett., 35, L21802, doi:10.1029/2008g1035859, 2008.

Liu, C. Y., Liu, G. R., Lin, T. H., Liu, C. C., Ren, H., and Young, C. C.: Using surface stations to improve sounding retrievals from hyperspectral infrared instruments, IEEE T. Geosci. Remote, 52, 6957-6963, doi:10.1109/tgrs.2014.2305992, 2014.

Marshall, J., Armour, K. C., Scott, J. R., Kostov, Y., Hausmann, U., Ferreira, D., Shepherd, T. G., and Bitz, C. M.: The ocean's role in polar climate change: asymmetric Arctic and Antarctic responses to greenhouse gas and ozone forcing, Phil. Trans. R. Soc., 372, 20130040, doi:10.1098/rsta.2013.0040, 2014.

Molnar, G. I. and Susskind, J.: Validation of AIRS/AMSU cloud retrievals using MODIS cloud analyses, in: Proc. SPIE 5806, Algorithms and Technologies for Multispectral, Hyperspectral, and Ultraspectral Imagery XI, 13 July 2005, 618-629, 2005.

Nghiem, S. V., Hall, D. K., Mote, T. L., Tedesco, M., Albert, M. R., Keegan, K., Shuman, C. A., DiGirolamo, N. E., and Neumann, G.: The extreme melt across the Greenland ice sheet in 2012, Geophys. Res. Lett., 39, L20502, doi:10.1029/2012gl053611, 2012

Olsen, E.: AIRS/AMSU/HSB version 6 changes from version 5, available at: http://disc.sci.gsfc.nasa.gov/AIRS/documentation/ v6_docs/v6releasedocs-1/V6_Changes_from_V5.pdf (last access: 4 December 2014), 2013a.

Olsen, E.: AIRS/AMSU/HSB version 6 retrieval flow, available at: http://disc.sci.gsfc.nasa.gov/AIRS/documentation/v6_ docs/v6releasedocs-1/V6_Retrieval_Flow.pdf (last access: 4 December 2014), 2013b.
Prakash, A.: Thermal remote sensing: concepts, issues and application, XIXth ISPRS Congress, Amsterdam, the Netherlands, 239243, 2000.

Riggs, G. A., Hall, D. K., and Ackerman, S. A.: Sea ice extent and classification mapping with the Moderate resolution Imaging Spectroradiometer airborne simulator, Remote Sens. Environ., 68, 152-163, doi:10.1016/s0034-4257(98)00107-2, 1999.

Riggs, G. A., Hall, D. K., and Salomonson, V. V.: MODIS sea ice products user guide to collection 5, available at: http:// modis-snow-ice.gsfc.nasa.gov/uploads/siug_c5.pdf (last access: 7 February 2015), 2006.

Scott, K. A., Li, E., and Wong, A.: Sea ice surface temperature estimation using MODIS and AMSR-E data within a guided variational model along the Labrador Coast, IEEE J. Sel. Top. Appl. Earth Observ. Remote Sens., 7, 3685-3694, doi:10.1109/jstars.2013.2292795, 2014.

Susskind, J., Blaisdell, J. M., Iredell, L., and Keita, F.: Improved temperature sounding and quality control methodology using AIRS/AMSU Data: The AIRS science team version 5 retrieval algorithm, IEEE T. Geosci. Remote, 49, 883-907, doi:10.1109/tgrs.2010.2070508, 2011.

Susskind, J., Blaisdell, J. M., and Iredell, L.: Improved methodology for surface and atmospheric soundings, error estimates, and quality control procedures: the atmospheric infrared sounder science team version-6 retrieval algorithm, APPRES, 8, 084994, doi:10.1117/1.JRS.8.084994, 2014.

Tian, B. J., Fetzer, E. J., Kahn, B. H., Teixeira, J., Manning, E., and Hearty, T.: Evaluating CMIP5 models using AIRS tropospheric air temperature and specific humidity climatology, J. Geophys. Res.-Atmos., 118, 114-134, doi:10.1029/2012jd018607, 2013.

Tobin, D. C., Revercomb, H. E., Knuteson, R. O., Lesht, B. M., Strow, L. L., Hannon, S. E., Feltz, W. F., Moy, L. A., Fetzer, E. J., and Cress, T. S.: Atmospheric radiation measurement site atmospheric state best estimates for atmospheric infrared sounder temperature and water vapor retrieval validation, J. Geophys. Res.-Atmos., 111, D09S14, doi:10.1029/2005jd006103, 2006.

von Storch, H. and Zwiers, F. W.: Statistical Analysis in Climate Research, Cambridge University Press, Cambridge, UK, 484 pp., 1999.

Wilks, D. S.: Statistical methods in the atmospheric sciences, Academic Press, San Diego, 467 pp., 1995.

Won, Y.-I.: Readme document for AIRS Level-3 version 5 standard products: daily (AIRH3STD, AIRX3STD, AIRS3STD), 8-day (AIRH3ST8, AIRX3ST8, AIRS3ST8) \& monthly (AIRH3STM, AIRX3STM, AIRS3STM), available at: http://disc.sci.gsfc.nasa.gov/TRMM/AIRS/documentation/ readmes/README.AIR-3ST.pdf (last access: 4 December 2014), 2008.

Yoo, J.-M., Won, Y.-I., Jeong, M.-J., Kim, K.-M., Shin, D.-B., Lee, Y.-R., and Cho, Y.-J.: Intensity of climate variability derived from the satellite and MERRA reanalysis temperatures: AO, ENSO, and QBO, J. Atmos. Sol.-Terr. Phys., 95-96, 15-27, doi:10.1016/j.jastp.2013.01.002, 2013.

Zheng, J., Li, J., Schmit, T., Li, J., and Liu, Z.: The impact of AIRS atmospheric temperature and moisture profiles on hurricane forecasts: Ike (2008) and Irene (2011), Adv. Atmos. Sci., 32, 319335, doi:10.1007/s00376-014-3162-z, 2015. 